\title{
World-Wide Lightning Location Using VLF Propagation in the Earth-Ionosphere Waveguide
}

Richard L. Dowden ${ }^{1}$, Robert H. Holzworth ${ }^{2}$, Craig J. Rodger ${ }^{3}$, János Lichtenberger ${ }^{4}$, Neil R. Thomson ${ }^{3}$, Abram R. Jacobson ${ }^{2}$, Erin Lay ${ }^{2}$, James B. Brundell, Thomas J. Lyons, ${ }^{5}$, Steven O'Keefe ${ }^{6}$,Zen Kawasaki, Colin Price ${ }^{8}$, Victor Prior ${ }^{9}$, Pascal Ortéga $^{10}$, James Weinman ${ }^{11}$, Yuri Mikhailov ${ }^{12}$, Oscar Veliz ${ }^{13}$, Xiushu Qie ${ }^{14}$, Gary Burns ${ }^{15}$, Andrew Collier ${ }^{16}$, Osmar Pinto Junior ${ }^{17}$, Ricardo Diaz ${ }^{18}$, Claudia Adamo ${ }^{19}$, Earle R. Williams ${ }^{20}$, Sushil Kumar ${ }^{21}$, G. B. Raga ${ }^{22}$, Jose M. Rosado ${ }^{23}$, Eldo E. Avila ${ }^{24}$, Mark A. Clilverd ${ }^{25}$, Thomas Ulich ${ }^{26}$, Peter Gorham ${ }^{27}$, Thomas J. G. Shanahan ${ }^{28}$, Thomas Osipowicz $z^{29}$, Gregory Cook ${ }^{30}$, and Yang Zhao ${ }^{31}$

${ }^{1}$ Low Frequency Electromagnetic Research, Ltd.

161 Pine Hill Road, Dunedin 9010, NZ

E-mail: dikdowden@gmail.com

${ }^{2}$ Dept of Earth and Space Sciences, University of Washington, Box 351310

Seattle, WA 98195-1310, USA

E-mail: bobholz@ess.washington.edu

${ }^{3}$ Physics Department, University of Otago PO Box 56, Dunedin, NZ

E-mail: crodger@physics.otago.ac.nz

${ }^{4}$ Eötvös Lorand University, Space Research Group Pazmany Peter s. I./A., H-1117, Budapest, Hungary E-mail: spacerg@sas.elte.hu

${ }^{5}$ Environmental Science Murdoch University Murdoch WA 6150 Australia E-mail: T.Lyons@murdoch.edu.au

${ }^{6}$ School of Engineering, Griffith University Nathan, QLD 4111, Australia

E-mail: s.okeefe@griffith.edu.au

${ }^{7}$ Department of Electrical, Electronics and Information Engineering,

Faculty of Engineering, Osaka University Yamada-Oaka 2-1, Suita, Osaka 565-0871 Japan

E-mail: zen@comm.eng.osaka-u.ac.jp

${ }^{8}$ Department of Geophysics \& Planetary Sciences Tel Aviv University, Ramat Aviv 69978, Israel E-mail: cprice@flash.tau.ac.il

${ }^{9}$ Instituto de Meteorologia, Rua Cao Aeroporto 1749-077 Lisboa, Portugal

E-mail: Victor.Prior@meteo.pt

${ }^{10}$ University of French Polynesia

BP 6570, 98702 Faaa Centre, French Polynesia E-mail: Pascal.Ortega@upf.pf
${ }^{11}$ ATG Building, University of Washington Box 351640, Seattle, WA 98195-1640, USA E-mail:weinman@atmos.washington.edu

${ }^{12}$ IZMIRAN, Troitsk Moscow region, 142190, Russia E-mail: yumikh@izmiran.ru

${ }^{13}$ Instituto Geofisico del Peru

Calle Badajoz No. 169, Urb. Mayorazgo

IV Etapa Ate Vitarte, Lima 03, Peru

E-mail: oveliz@jro.igp.gob.pe

${ }^{14}$ Lab. for Middle Atmosphere and Global Environment Observation (LAGEO), Institute of Atmospheric Physics Chinese Academy of Sciences, Beijing 100029, China E-mail: qiex@mail.iap.ac.cn

${ }^{15}$ Ice, Ocean, Atmosphere \& Climate Australian Antarctic Division

203 Channel Highway, Kingston, Tasmania 7050, Australia E-mail: Gary.Burns@aad.gov.au

${ }^{16}$ Hermanus Magnetic Observatory

PO Box 32, Hermanus, 7200 , South Africa E-mail: colliera@ukzn.ac.za

${ }^{17}$ Chefe do Grupo de Eletricidade Atmosférica (ELAT), DGE/INPE

Av. Astronautas 1758, S.J. Campos, SP, 12240-540, Brazil E-mail: osmar@dge.inpe.br

${ }^{18}$ Laboratorio Alta Tension, Universidad Nacional Tucuman Av. Independencia 1800 - (4000) S.M. de Tucuman, Argentina

E-mail: rdiaz@herrera.unt.edu.ar

${ }^{19}$ Institute of Atmospheric Sciences and Climate ISAC-CNR, Area di Ricerca, di Tor Vergata

Via del Fosso del Cavaliere, 100, 00133 Roma, Italy E-mail: claudia.adamo@ifa.rm.cnr.it 


\footnotetext{
${ }^{20}$ Massachusetts Institute of Technology

Parsons Lab Rm. 48-319, Cambridge, MA 02139-4307, USA

E-mail: earlew@II.mit.edu
}

\author{
${ }^{21}$ Physics Department \\ University of the South Pacific, Suva, Fiji \\ E-mail: kumar_su@usp.ac.fj
}

${ }^{22}$ Centro de Ciencias de la Atmosfera

Universidad Nacional Autonoma de Mexico

Ciudad Universitaria, 04510 Mexico DF, Mexico

E-mail: raga@servidor.unam.mx

${ }^{23}$ Electrical and Computer Engineering Dept. University of Puerto Rico

S-224 Stefani Building, Mayaguez, 00681 Puerto Rico

E-mail: jrosado@ece.uprm.edu

${ }^{24}$ Fa.M.A.F., Universidad Nacional de Cordoba

Ciudad Universitaria, 5000 Cordoba, Argentina

E-mail: avila@famaf.unc.edu.ar

${ }^{25}$ Physical Sciences Division

British Antarctic Survey (NERC)

High Cross, Madingley Road, Cambridge, CB3 OET UK

E-mail: macl@bas.ac.uk
${ }^{26}$ Sodankyla Geophysical Observatory, Tähteläntie 62

FIN-99600 Sodankyla, Finland

E-mail: thu@sgo.fi

${ }^{27}$ Dept. of Physics and Astronomy, University of Hawaii 2505 Correa Rd., Honolulu, HI 96822 USA

E-mail: gorham@phys.hawaii.edu

${ }^{28}$ Seismology and Geomagnetism Group British Geological Survey (NERC)

West Mains Road, Edinburgh, EH9 3LA, Scotland

E-mail: tjgs@bgs.ac.uk

${ }^{29}$ Dept. of Physics, National University of Singapore Singapore

E-mail: phyto@nus.edu.sg

${ }^{30}$ Dept. of Electronic and Electrical Engineering

University of Sheffield

Mappin Street, Sheffield, S1 3JD, UK

E-mail: g.cook@sheffield.ac.uk

${ }^{31}$ Cold and Arid Regions Environmental and Engineering Research Institute,

Chinese Academy of Sciences, 320 Donggang West Road,

Lanzhou 730000, Gansu, China

E-mail: icae2007@|zb.ac.cn

\begin{abstract}
Worldwide lightning location (WWLL) using only 30 lightning sensors has been successfully achieved by using only VLF propagation in the Earth-ionosphere waveguide (EIWG). Ground propagation or mixed "sky" and ground propagation is avoided by requiring evidence of Earth-ionosphere waveguide dispersion. A further requirement is that the lightning strike must be inside the perimeter defined by the lightning sensor sites detecting the stroke. Under these conditions, the time and the location of the stroke can be determined, along with the rms errors. Lightning strokes with errors exceeding $30 \mu s$ or To assist with identifying impulses from the same lightning stroke, the lightning sensor threshold is automatically adjusted to allow an average detection rate of three per second. This largely limits detection to the strongest $4 \%$ of all lightning strokes, of which about $40 \%$ meet the accuracy requirements for time and location.
\end{abstract}

Keywords: Lightning; VLF propagation; Earth-ionosphere waveguide

\title{
1. Introduction
}

$\mathbf{T}$ his lightning location network was conceived by Low Frequency Electromagnetic Research (LFEM), set up by one of us in Dunedin, New Zealand, on retirement from the University of Otago where the first lightning sensor was sited. The intention was to locate the lightning strokes that trigger "red sprites," which were being detected by LFEM both optically and by VLF perturbations at two sites near Darwin, Australia. At that time (1995-2001), the only available lightning location network (Kattron, using time-ofarrival) served southeast Australia, where most of the population resides. Initially, LFEM used VLF MDF (magnetic direction finding) sensors at the two Darwin sites, together with a VLF time-ofarrival (TOA) sensor at the Dunedin site. This was of limited success, even with the later addition of VLF time-of-arrival at Perth, Australia.

It was only when three more sensors were set up in August 2001, at Osaka, Japan; Singapore; and Brisbane that there were a sufficient number of sensor sites for lightning location by VLF time-of-arrival only (no magnetic direction finding). While the geographical extent of this network $\left(70^{\circ}\right.$ in longitude, $80^{\circ}$ in latitude) was far more than needed for sprites seen from Darwin, it resulted in LFEM being invited as an Industry Partner by the Australian Research Council to develop lightning location over sparsely populated areas in the northern half of Australia. This made the Worldwide Lightning Location Network (WWLLN) possible.

Gradually, the network was extended via contacts long known through international scientific conferences and ex-graduate students now spread around the world. By the beginning of 2003, the lightning location network (LLN) had become worldwide (WW). Currently, there are 30 WWLLN lightning receiving sites distributed around the world in longitude, and from the Antarctic to the Arctic in latitude. 


\section{Propagation}

The use of the middle part of the VLF band ( 6 to $22 \mathrm{kHz}$ out of 3 to $30 \mathrm{kHz}$ for the full VLF band) is ideal for very-long-range lightning location. Propagation over distances of about $10,000 \mathrm{~km}$ is common, but since the attenuation in this band is around 1 or $2 \mathrm{~dB}$ per $1000 \mathrm{~km}$ (depending on propagation direction and time of day), the attenuation for propagation 'round the world (RTW), or even half-way around the world, is prohibitive. In any case, if a sferic arrived at a lightning sensor from a lightning stroke $10,000 \mathrm{~km}$ distant, but after traveling three-quarters of the way around the world instead of one-quarter, the time of arrival would be so wrong so that the location would simply be rejected. At higher frequencies (LF, MF, and HF), propagation is far more limited in range and unreliable for location by timing, unless restricted to groundwave propagation.

The WWLLN exclusively uses propagation in the Earth-ionosphere waveguide (EIWG). It has been found that mixing "skywave" (Earth-ionosphere waveguide) propagation with "groundwave" (line-of-sight) propagation leads to significant LL (lightning location) errors. This has long been known in the case of shortrange (a few $100 \mathrm{~km}$ ) networks using time-of-arrival and/or magnetic direction finding. These avoid skywave propagation by using only the first few microseconds of the lightning impulse [1], which is equivalent to limiting the low frequencies to a few hundred $\mathrm{kHz}$. Earth-ionosphere waveguide propagation shows the characteristic phase as a function of frequency shape of waveguide dispersion. Superposition of groundwave signals changes this shape to give a bad correlation with the theoretical shape, as well as to give it the opposite trend. Impulses that show this opposite trend are not included as genuine lightning impulses ("sferics").

VLF propagation in the Earth-ionosphere waveguide is largely restricted to the quasi-TE and quasi-TM modes. The dispersionless TEM mode is possible, but highly attenuated at VLF. The "quasi" term arises because - unlike a waveguide formed by two infinite, conducting, parallel planes - the upper bound (the ionosphere) is not sharply defined, is partly a conductor and partly a dielectric, and both properties depend on frequency. The lower bound, particularly if it is a smooth ocean, is a much better approximation to a horizontal plane conductor. The boundary conditions at this conductor require that the horizontal component of the electric field be zero, so only the TM (transverse magnetic) modes, the electric field of which is vertical at the smooth ocean surface, provide the VLF signal we need.

A monochromatic wave propagating in the Earth-ionosphere waveguide in both the $\mathrm{TM}_{1}$ and $\mathrm{TM}_{2}$ modes can, at some point along the path, have zero amplitude if the two modes have equal amplitude and opposite phase at that point. The $3 \mathrm{~dB}$ bandwidth of the spherics as seen by the lightning receivers is over $3: 1(6 \mathrm{kHz}$ to $22 \mathrm{kHz}$ ). This means that a sferic propagating in the Earth-ionosphere waveguide in both the $\mathrm{TM}_{1}$ and $\mathrm{TM}_{2}$ modes can, at some frequency along the path, have zero amplitude if the two modes have equal amplitude and opposite phase at that frequency. This has been observed [3], but it is rarely significant, and it is rejected in any case if it affects the dispersion curve.

The typical lightning return-stroke current decays to half peak in about $40 \mu \mathrm{s}$ [2]. The radiated pulse is dispersed into a wave train in the Earth-ionosphere waveguide. For $10 \mathrm{Mm}$ propagation, the amplitude of this wave train rises from the noise floor to maximum in about $200 \mu \mathrm{s}$, and then decays to half maximum in about $400 \mu \mathrm{s}$ [3]. There thus is no sharp pulse from which to measure the time of arrival. Instead, we do the following. The VLF signal, comprising the sferics, VLF communication transmissions, power-line harmonics, etc., is continuously sampled at $48 \mathrm{kS} / \mathrm{s}$ - as is the GPS PPS (pulse per second) for precision timing - and stored in a buffer. When the difference between two consecutive samples exceeds a predetermined threshold, 64 samples are grabbed from the buffer: 16 samples $(333 \mu \mathrm{s})$ from before the grab and 48 samples $(1000 \mu \mathrm{s})$ after, which contains the whole waveform. From the rate-of-change of wave phase with respect to frequency, we get the time of group arrival (TOGA) to within one microsecond or so [3].

The geometric mean of the band limits $(6 \mathrm{kHz}$ and $22 \mathrm{kHz})$ over which we make the measurement of the time of group arrival is about $12 \mathrm{kHz}$. At this frequency, the Earth-ionosphere waveguide group velocity during the day is equal to that at night [6], at about $0.9922 c$ [0.9922 times the speed of light in vacuum). This frequency is near the maximum spectral density of lightning radiation $[7,8]$, which extends from a few hertz to optical frequencies. The wavelength of this maximum is about $30 \mathrm{~km}$.

\section{VLF Antennas}

Most of the antennas discussed in this journal are for millimeter wavelengths, so engineers designing these need a drastic rethink when the wavelength increases some seven-and-one-half orders of magnitude. VLF antennas used for lightning detection have dimensions of less than $3 \mathrm{~m}$, and so are less than a tenthousandth of a wavelength. Being so small, loop antennas are sensitive only to magnetic fields, are impervious to electric fields, and have very low output impedance. VLF magnetic fields are shielded (cancelled) by induced currents, so adequate shielding from magnetic fields produced by electric-power reticulation on university and institute campuses requiring extremely good (and so, very thick) conductors is not feasible. At the other extreme are vertical whip antennas of about $1 \mathrm{~m}$ long, "counterpoised" by a longer metal pole, hand rails, etc. Such antennas are sensitive only to electric fields, are impervious to magnetic fields, and have very high output impedance (almost purely capacitive at around $15 \mathrm{pF}$; the impedance at $10 \mathrm{kHz}$ is $\sim 1 \mathrm{M} \Omega$ ). VLF electric fields are shielded (cancelled) by induced charge, so quite poor conductors can provide adequate shielding from electric fields produced by electric-power reticulation on university and institute campuses. Having the power lines underground or behind the walls and roofs of ferro-concrete buildings may thus be all that is needed. What is to be avoided is the unintentional shielding of the VLF electric fields of the sferics: the lightning impulses needed for lightning location.

For VLF $(\lambda \sim 30 \mathrm{~km})$ sources within about $5 \mathrm{~km}(\lambda / 2 \pi)$ of the VLF antenna, the induction field dominates, so for the dimensions of campuses and city blocks, VLF can be approximated by zero frequency. The VLF-wave electric field can thus be approximated by an electrostatic field. As pointed out in Section 2, the electric field at a plane horizontal ground is vertical. An ideal site for the VLF antenna would therefore be on a horizontal conducting plane with horizontal dimensions of a few wavelengths. Obviously, such a site is certainly not to be found on a university or institute campus. We have to compromise, because we need electric power for the VLF receivers and processing computers, we need the Internet for continuous transmission of the times of group arrival, and, in particular, the VLF receiving sites must be convenient to the authors of this paper, who make the WWLLN work. This means that the VLF antennas must be suitably sited on the cam- 
puses of their universities or institutes. These campuses, being different from the ideal horizontal conducting plane, greatly affect the VLF electric field in magnitude and direction. This can be used to advantage: suitable sited on campus, the signal from the VLF antenna can be greatly enhanced; badly sited, the signal from the VLF antenna can be reduced to the noise level.

Figure 1 shows the outline of three buildings on campus, well-separated from other buildings (buildings, masts, trees, etc., not shown are "infinitely" remote). All three buildings have flat roofs, free of antennas and dishes, and even free of parapets. At altitudes of more than twice the height of the tallest building, the equipotential surfaces are nearly plane, nearly horizontal, and nearly evenly spaced. The electric field is thus nearly uniform, vertical, and nearly independent of altitude. The electric field is everywhere normal to the equipotential surfaces, and equal in magnitude to the potential gradient: high where consecutive equipotential surfaces are close together, and low where they are far apart.

From Figure 1, we see that the highest electric fields, and so the best VLF antenna sites, are at (actually above) $a$ or $b$, the outside edges of the roofs of tall buildings. The electric field, being normal to the equipotential surfaces, is tilted out and away from vertical, so the VLF antenna can also be tilted with advantage. This is particularly important if the roof of the building has a forest of antennas and dishes, as is often the case on buildings for geophysicists and electrical engineers. The roof of the middle building (above $c$ ) is partly shielded by the higher buildings on either side. Comparing the distance of the equipotential surface above this roof at $c$ with the distance of the same equipotential surface from $a$ or $b$ implies that a short $(1 \mathrm{~m}) \mathrm{VLF}$ antenna site at $c$ would receive only a tenth of the field of one sited at $a$ or $b$.

Siting the VLF antenna on the ground between buildings at $d$ or $e$, or close to an isolated tall building at $f$ or $g$, can result in no usable signal at all.

\section{Transmitter (Lightning-Stroke) Identification}

In many respects - with one major difference - the Omega global navigation system [4] was similar to the WWLLN. Although Omega appeared to use phase differences at different frequencies, this was equivalent to using the rate of change of phase with respect to frequency to get the group travel time from each transmitter to the receiver. Omega thus used and WWLLN thus uses the time of group arrival: Omega to get the receiver position, knowing the exact location of the VLF transmitters, and WWLLN to get the transmitter (lightning-stroke) position, knowing the exact positions of the WWLLN receivers.

The major difference between Omega and WWLLN is that the eight Omega transmitters identified themselves by transmitting a unique frequency. In contrast, a lightning impulse (sferic) appears much the same as any other. Locating lightning-stroke $\mathrm{X}$ requires the times of group arrival at a minimum of four receivers, each of which are receiving about 100 sferics per second from distances in all directions of up to about $13 \mathrm{Mm}$.

Of the four (or more) WWLLN sites that "see" lightningstroke X, the nearest to the stroke may be only $1000 \mathrm{~km}$ from it, while the furthest may be over $13,000 \mathrm{~km}$ from it. The spread in times of group arrival would thus typically be about $30 \mathrm{~ms}$.
Superimposed on this set of times of group arrival are the times of group arrival from strokes other than stroke $\mathrm{X}$, which are arriving at these WWLLN sites at a random rate of about 100 per second, and so with a typical (but very variable) separation of around $10 \mathrm{~ms}$. This means that several sferics (and time-of-group-arrival values) from other strokes will arrive at each of the WWLLN sites receiving sferics from stroke $X$ during the $30 \mathrm{~ms}$ it takes to get the sferics from stroke X. All of these times of group arrival are sent to the central processing computer (CPC) for analysis. Each time of group arrival carries a label to say which WWLLN station received it, but no label to say which lightning stroke produced it.

To resolve this, consider the US nationwide network of ARSI time-of-arrival sensors (see [5, Section 17.5 , p. 565]), which used about 60 time-of-arrival receivers, a few hundred $\mathrm{km}$ apart, and which used only a few microseconds of the lightning pulse to ensure that the lightning pulse arrived without a skywave component. This meant that a stroke to be detected occurred within a few hundred $\mathrm{km}$ of a least four lightning sensors. The times of arrival (TOAs) could all be the same at each of the four stations, but were more likely spread over, say, $1 \mathrm{~ms}$, corresponding to the furthest of the four lightning sensors being $300 \mathrm{~km}$ further from the lightning stroke than the nearest. The National Lightning Detection Network central processing computer gets a short $(\sim 1 \mathrm{~ms})$ clump of times of arrival from the designated four lightning sensors. Did this result in overlapping clumps?

To answer that last question, consider the US state, Florida, which gets the most lightning. An estimate [5] is that a given square meter would be struck by lightning once in $10^{5}$ years, or

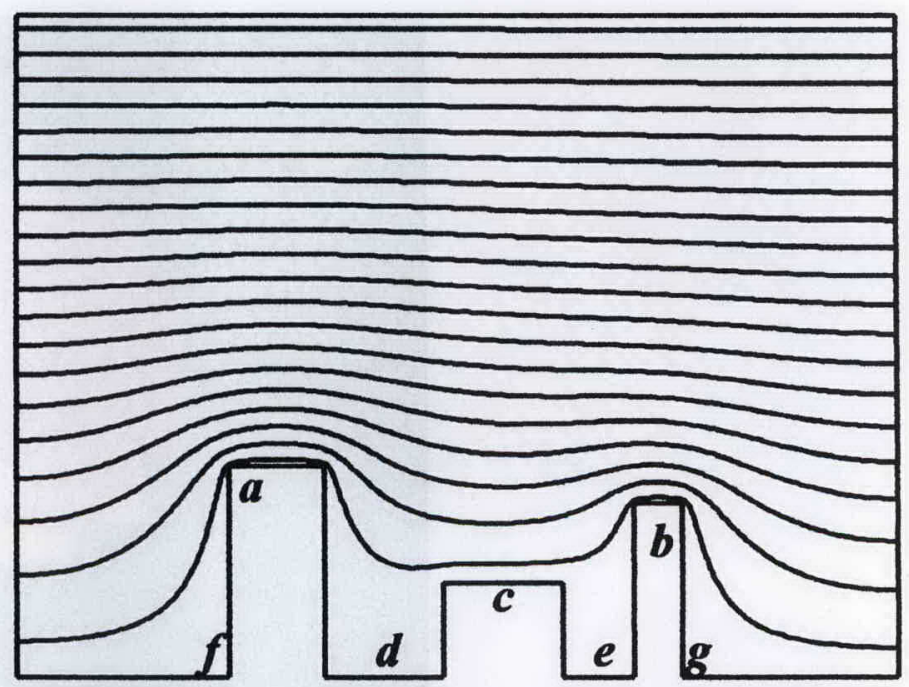

Figure 1. Electric equipotential surfaces calculated from Laplace's equation $\left(\nabla^{2}=0\right)$ for the boundary conditions: the outline of the three buildings and the ground (an infinite horizontal plane) on which they stand was at zero potential, and the top border of this picture was an infinite horizontal plane at $100 \%$ potential. All were perfect conductors. The equipotential surface immediately above the buildings and ground was at $\mathbf{2 . 5} \%$. Thereafter, consecutive equipotential surfaces increased in $5 \%$ steps, except for the last step $(2.5 \%)$. Thus, beginning at the bottom, the percent potentials were: $0,2.5,7.5,12.5, \ldots$ $92.5,97.5,100$. The electric field was everywhere normal to the equipotential surfaces. The letters $a, b, c, \ldots g$ indicate good and bad locations for the very small VLF antenna, as discussed in the text. 
about once in $3 \times 10^{12}$ seconds. If we expand the area to $10^{12} \mathrm{~m}^{2}$ (a circular area of radius $\sim 600 \mathrm{~km}$ that should enclose four or more sensors), we would expect one stoke per three seconds. However, many of these would be part of a flash of strokes separated by only a few tens of ms. Even so, the likelihood of overlapping clumps, each only $1 \mathrm{~ms}$ long, is very small.

Clearly, a requirement for WWLLN was to somehow cause the times of group arrival from individual lightning strokes to form non-overlapping clumps. A second requirement was to detect and suppress bad locations caused by including one or more sferics (and corresponding times of group arrival) from lightning strokes other than the stroke the location of which is sought. A third was to detect and remove "rogue" times of group arrival from the location algorithm. This last requirement is conditional on the number of times of group arrival exceeding the minimum number allowed. We now discuss how we incorporated these requirements.

At no time was the sensitivity of the WWLLN lightning sensors set high enough to detect all of the globe's lightning strokes. However, during the first year, when we had only six receiver sites, a thunderstorm over one of the sites caused hundreds of sample triggers per second and overloaded the whole network, such as it

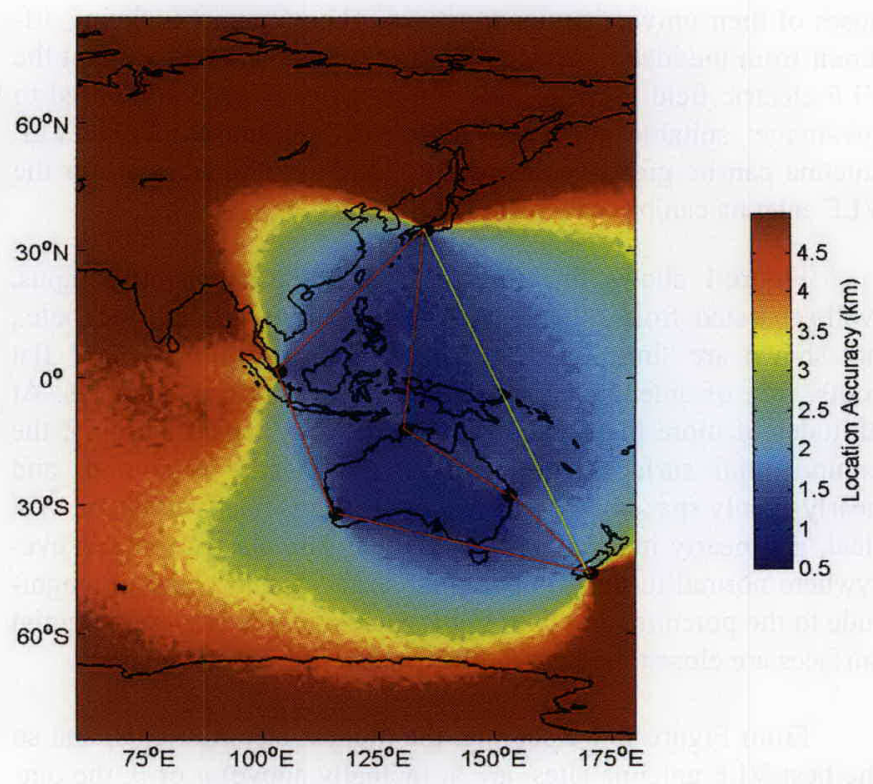

Figure 2. A calculation of the location accuracy of lightning strokes at any point on the map, assuming that each stroke was detected by all six receivers (black dots), and that the residual error was $5 \mu$ s at all points. Only inside the area bounded by the red lines was the location error determined by the residual error. The location error increased very sharply outside of sharp corners.

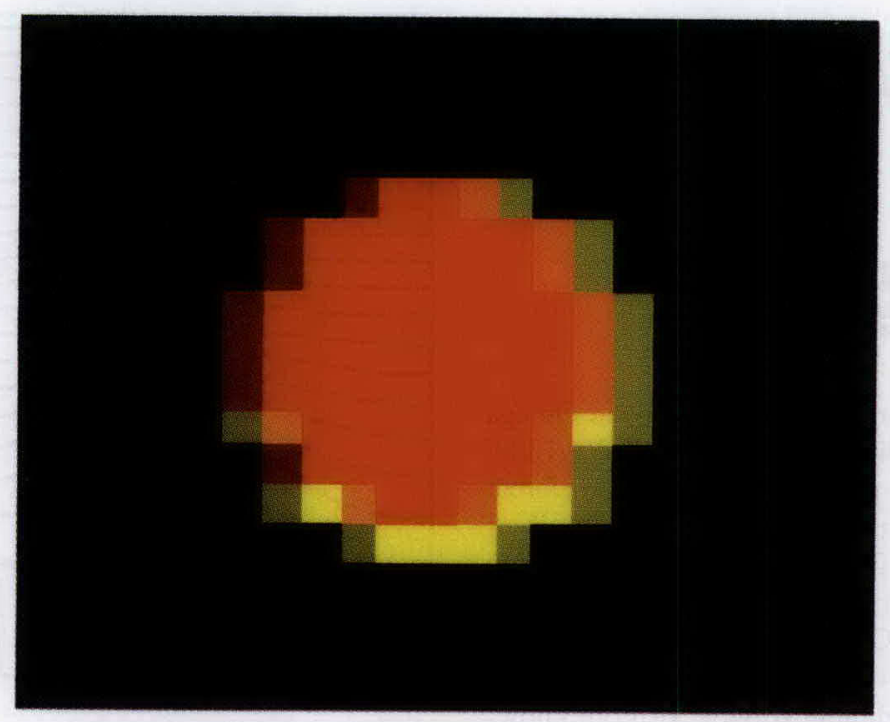

Figure 4. Strokes 10 minutes apart but only $15 \mathrm{~km}$ apart in location. 


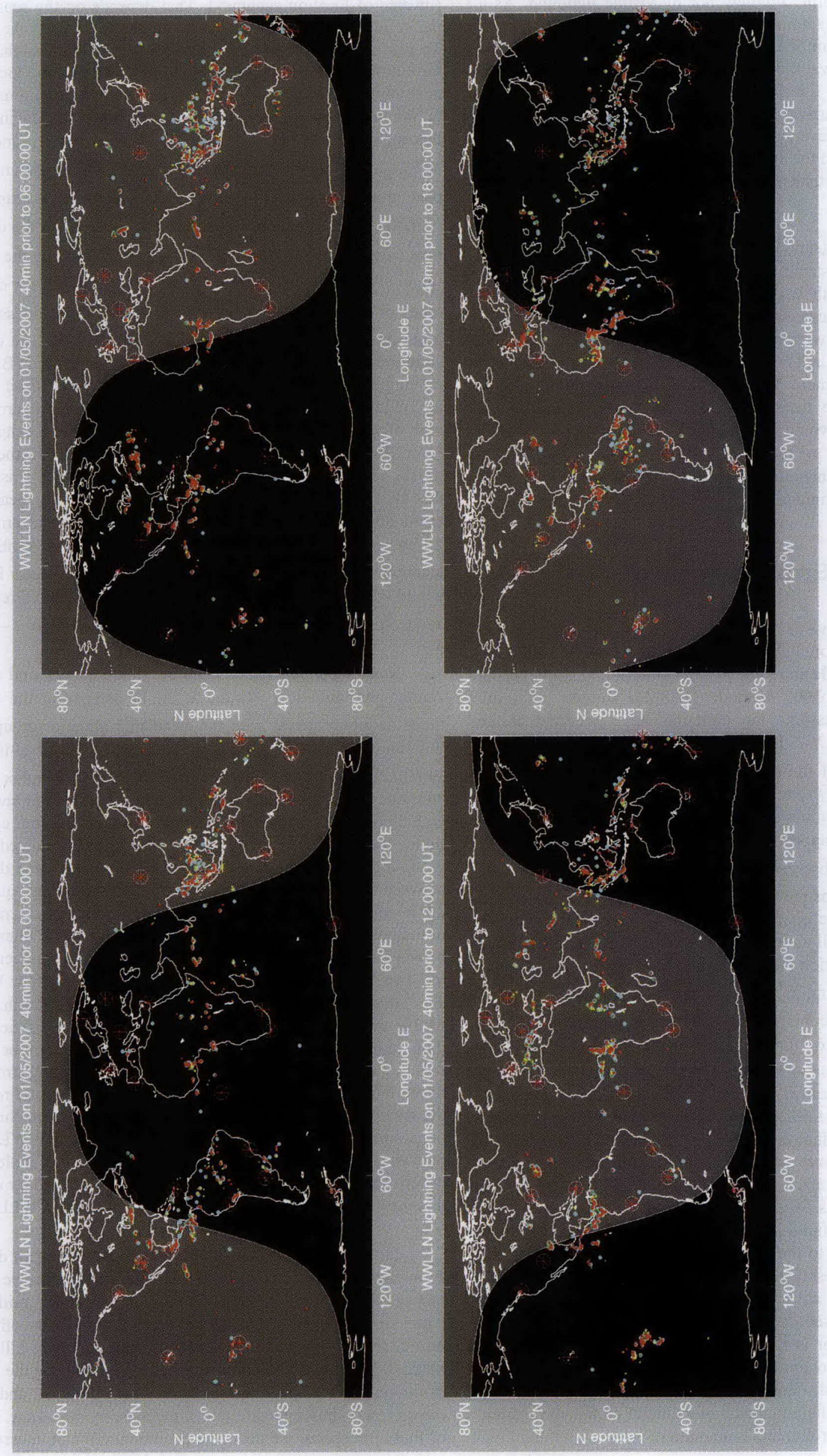

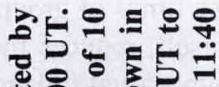

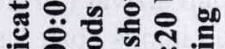
击

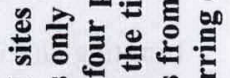
乙

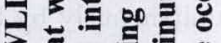

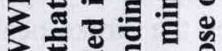
등 울

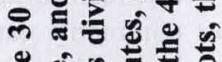
요을 च है

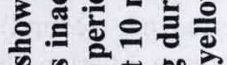
क สิ जี

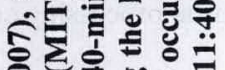
강

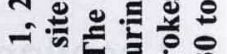

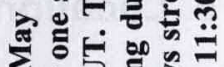
중

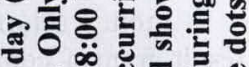
잉

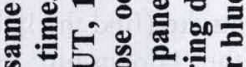

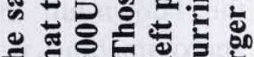

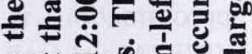
Б등

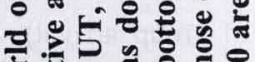
눙용 \%

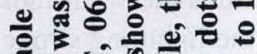

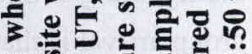
ฐ 을을 느의

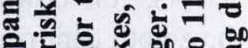

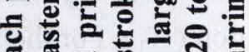

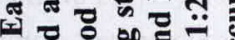
政 ส

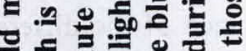

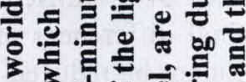
它

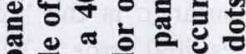
군

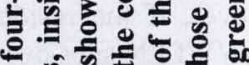
《梂 《欧 نे

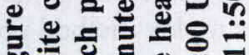

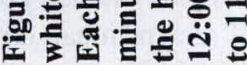


was at that time. These triggers were caused by electric-field pulses due to the thunderstorm, although not by visible lightning. As a result, we added an automatic threshold control (ATC) to each lightning sensor to limit the average (over a few minutes) number of times of group arrival transmitted to the central processing computer. This automatic threshold control number is currently set to three times of group arrival per second at each WWLLN site. This, in itself, reduces the overlap of clumps of "monostroke" times of group arrival (all from the same lightning stroke) to the extent that the clumps span less than $30 \mathrm{~ms}$ and are typically spaced $300 \mathrm{~ms}$ apart.

Limiting the detection rate limits capture (for analysis and lightning location) to strong strokes. Comparison of strokes located simultaneously by both WWLLN and an MF network that measures the stroke peak current revealed that strokes with peak currents less than $25 \mathrm{kA}$ were rarely captured by the WWLLN. Those most commonly captured had peak currents of $\sim 50 \mathrm{kA}$ (stronger lightning strokes are more easily captured, but occur more rarely). Setting the automatic threshold control to higher values (more sferics per second) would capture weaker lightning, but would increase overlap and increase the cost to all the hosts of our WWLLN sites of transmitting the times of group arrival to the central processing computer.

\section{Location-Error Estimate and Limiting}

From a set of five or more times of group arrival assumed to result from a common lightning stroke, we locate the lightning stroke (find the latitude and longitude of the lightning stroke) using the "down-hill simplex" method (DHSM) [9]. As a zeroth approximation, we assume the lightning stoke occurred at the WWLLN site (call it $X_{0}$ ) that received it first (has the earliest time of group arrival). All the other WWLLN sites that detected the same lightning strike have later times of group arrival. We now calculate what those times of group arrival would have been had the lightning stroke happened at $X_{0}$. The earliest observed time of group arrival is that observed at $X_{0}$, so that that time of group arri$\mathrm{val}$ is the reference for the other calculated times of group arrival that differ from those observed. From the set of differences, or "errors," the down-hill simplex method gives a direction to move the zeroth approximation $\left(X_{0}\right)$ "down hill" to a better approximation $\left(X_{1}\right)$. For the lightning stroke at $X_{1}$, we calculate the times of group arrival, compare them to the observed times of group arrival, etc., find $X_{2}$, and so on for many further iterations, until the variance of the differences is not reduced by a further iteration. The final differences are called the "residuals:" what is left over and cannot be reduced by further iteration. The square root of the final variance is the "residual error." Lightning locations that have a residual error $>30 \mu$ s are suppressed (deleted from records). However, if the residual error exceeds $30 \mu \mathrm{s}$ and if the number of WWLLN sites exceeds five, each providing a time of group arrival, we can examine the individual residuals, delete the time of group arrival corresponding to the worst residual, and run the down-hill simplex method process with the remaining times of group arrival. If the residual error still exceeds $30 \mu \mathrm{s}$ and if the number of WWLLN sites still exceeds five, this can be repeated more times, until the residual error is reduced below $30 \mu$ s or the number of WWLLN sites (and so times of group arrival) is reduced to five, whichever comes first. This procedure works well if the worst residual is due to overlap (the result of a time of group arrival from a different lightning stroke) and is an outlier.
The residual error is not a direct indication of location error (inverse of location accuracy). That depends on the sensitivity of the residual error to displacement of the lighting-stroke position. To illustrate this, imagine the Earth to be one-dimensional, so that the Earth is just a single very long line. For lightning location, we need only two receivers, $\mathrm{A}$ and $\mathrm{B}$, since any lightning must occur on the line. Now, a lightning stroke occurs at $X$, producing a sferic that arrives at WWLLN receiver $\mathrm{A}$ at time $T O G A_{A}$ and at $\mathrm{B}$ at $T O G A_{B}$. Our computer seeks to locate $X$ using the down-hill simplex method discussed above. Since $T O G A_{A}$ is earlier than $T O G A_{B}$, the zeroth approximation, $X_{0}$, is at A, so the calculated time of group arrival for $\mathrm{A}$ is $T O G A_{A}$. In comparing the observed times of group arrival $\left(T O G A_{A}\right.$ and $\left.T O G A_{B}\right)$ with the calculated times of group arrival, suppose $T O G A_{B}-T O G A_{A}$ is less than the group travel time from WWLLN receiver A to $B$. The down-hill simplex method "decides" that "down hill" is towards B, because moving this way initially increases the calculated time of group arrival at $\mathrm{A}$ and decreases the calculated time of group arrival at B, both of which reduce the error until eventually the residual is zero (even though the down-hill simplex method may overshoot a few times), and the lightning stroke is precisely located. This assumes that the observed times of group arrival have no measurement error. Suppose instead that the random measurement error in the difference $T O G A_{B}-T O G A_{A}$ is $10 \mu \mathrm{s}$. This might be attributed to a location error of $x \mathrm{~km}$ along the line between $\mathrm{A}$ and $\mathrm{B}$, which would change both $T O G A_{B}$ and $T O G A_{A}$ in opposite directions by $x / c=5 \mu \mathrm{s}$, where $c$ is the speed of light, $0.3 \mathrm{~km} / \mu \mathrm{s}$, so $x \sim 1.5 \mathrm{~km}$.

Now, suppose another lightning stroke occurs, and again the zeroth approximation, $X_{0}$, is at $\mathrm{A}$. In comparing the observed times of group arrival with the calculated times of group arrival, this time $T O G A_{B}-T O G A_{A}$ is equal to the group travel time from WWLLN receiver A to $B$. The down-hill simplex method "decides" that "down hill" is in the opposite direction, away from $\mathrm{B}$ and so also from A. Moving this way increases the calculated time of group arrival at $\mathrm{A}$ and increases the calculated time of group arrival at B by exactly the same amount, so the difference between the calculated times of group arrival remains equal to the difference between the observed times of group arrival, regardless of the position of $X$. In other words, the location of $X$ when it is not between A and B is impossible. This effect can also occur on the real two-dimensional Earth's surface if we use only four WWLLN sites, three of which are closely grouped and the fourth is much further away. The outline of the set on the surface of the Earth is thus wedge-shaped, and then an enduring thunderstorm occurs outside the wedge near the point of the wedge. Lightning strokes produced by this storm are correctly located on the great circle along the axis of the wedge, but at different places along it. Such situations are reduced by requiring a minimum of five WWLLN sites receiving the sferics from the lightning stroke, which are less likely to form such wedge shapes. They are now eliminated by requiring that the lightning stroke is surrounded by receiving WWLLN sites.

The effect just described arises because in certain directions from the position of the lightning stroke, the geometric arrangement of the receiving WWLLN sites is such that the residual error varies very slowly so that its variation is masked by other small errors, resulting in false minima confusing the down-hill simplex method. We detect and eliminate these by measuring the variation of the residual error along four directions: N, NE, E, and SE, and the corresponding opposite four directions, by symmetry. For each of these directions, we deduce a positional error or uncertainty for 
that direction. If the error for any of the directions exceeds $10 \mathrm{~km}$, we delete that location measurement from the records.

It was pointed out above that the residual error is not a direct indication of location error (inverse of location accuracy). However, it is in special cases. Consider four WWLLN sites arranged on the surface of the Earth in the form of a square, the diagonals of which are aligned N-S and E-W. The four WWLLN sites can then be designated N, E, S, and $\mathrm{W}$. The dimensions of the square are not important, but we suppose them to be a few Mm to ensure that our approximations are valid. A lightning stoke exactly at the center of the square would be detected at all four WWLLN sites at the same instant, that is, the times of group arrival (TOGA) of the sferic would be the same. Now suppose a lightning stroke occurs $1.5 \mathrm{~km}$ North of the center of the square, and so is that much closer to $\mathrm{N}$, the northernmost WWLLN site; that much further away from S; and a trivial distance (a meter or so) further away from both $\mathrm{E}$ and W. From the one-dimensional case discussed above, the time of group arrival at N (the northernmost WWLLN site) will be reduced $5 \mu \mathrm{s}$, while the time of group arrival at $\mathrm{S}$ (the southernmost WWLLN site) will be increased $5 \mu$ s. TOGA $(S)-T O G A(N)$ will thus increase by $10 \mu \mathrm{s}$. The opposite will result if a lightning stroke occurs $1.5 \mathrm{~km}$ south of the center of the square, except it will be the same trivial distance further away from both $\mathrm{E}$ and W. If many more lightning strokes occur along the N-S diagonal at random distances from the center of the square with a standard deviation (SD) of $1.5 \mathrm{~km}$, the standard deviation of the time-of-group-arrival difference will be $10 \mu \mathrm{s}$. We have assumed that the displacement is from the exact center of the square, and exactly along the N-S diagonal. This assumption was to avoid any change to the times of group arrival at E and W. Since the diagonals are thousands of times longer than the displacements used here, we can expect the same results provided the random displacements are parallel to N-S but displacements normal to N-S are constant (and very small compared to the dimensions of the square).

Had we chosen the E-W diagonal instead of the N-S diagonal, then a random distribution of strokes along (or merely parallel to) the E-W diagonal with a standard deviation of $1.5 \mathrm{~km}$ would give a standard deviation of the time of group arrival E-W differences of $10 \mu \mathrm{s}$. We now replace the random displacements in only one direction (parallel to one diagonal) with independent random displacements in both directions, E-W (which we call $x$ ) and N-S $(y)$, such that both displacement components, $x$ and $y$, have a standard deviation of $1.5 \mathrm{~km}$ (giving a radial displacement standard deviation of $1.5 \sqrt{2} \mathrm{~km}$ ), so the standard deviation of the differences in times of group arrival at diagonally opposite WWLLN sites at the corners of the square are $10 \mu \mathrm{s}$.

Having found the effect on the times of group arrival of a normal distribution of lightning strokes about the center of the square, we reverse the process to find the effect of random measurement errors of the times of group arrival (all with the same standard deviation) on the lightning-stroke location error. Moving a lightning stroke towards a WWLLN site moves it away from one in the opposite direction because the WWLLN sites are fixed, so the times of group arrival are coupled. To estimate stroke-location errors from independently random time-of-group-arrival errors, to get a standard deviation of $10 \mu \mathrm{s}$ in the time-of-group-arrival differences for times of group arrival at diagonally opposite WWLLN sites, the standard deviation of each individual time of group arrival should be $10 / \sqrt{2} \mu$ s. The location error in $\mathrm{km}$ per microsecond of time-of-group-arrival error (assuming this to be the residual error) is hence $1.5 \sqrt{2} \mathrm{~km}$ divided by $10 / \sqrt{2} \mu \mathrm{s}$, which is $c$, the speed of light, $0.3 \mathrm{~km} / \mu \mathrm{s}$. This is deduced for a stroke in the center of a square defined by four WWLLN sites, the times of group arri$\mathrm{val}$ at which have the same error standard deviation, resulting in a purely radial error standard deviation (the same in all directions).

Thus, at least for the special center-of-square model, the relationship between the location error and the residual error is simply $c$, the speed of light. Is this true for every point inside the square?

To check this, we considered a large array of points in the square. At each point in the square, we moved the "lightning stroke" by small but random displacements of $x$ and $y$ such that the radial displacements had a normal distribution of a given standard deviation that was the same for all points, while all displacement directions were uniformly represented. This also showed that the relationship between the location error and the residual error is simply $c$, the speed of light, at all points inside the square.

This process was also used to make the map shown as Figure 2. This map extends in latitude from Antarctica to beyond the Arctic, and in longitude to include all of Asia. It shows the original six lightning-location sites (black-filled circles) of what was to become the WWLLN. Following the red lines clockwise from the right-most, the sites are Dunedin, Perth, Singapore, Osaka, Darwin, and Brisbane. For each point of the map, the time of group arrival at each of the six sites of a sferic (from a stroke) at that point was calculated. Taking this point and the resulting times of group arrival as a reference, the "stroke" was moved randomly in distance and direction about that point. The standard deviation of the radial displacement required to make the residual error equal $5 \mu \mathrm{s}$ was recorded as a color shown on the scale.

The highest location accuracy was for strokes inside the area bounded by the red lines, where the error was $\sim 1.5 \mathrm{~km}$, which was $c(0.3 \mathrm{~km} / \mu \mathrm{s})$ times the residual error $(0.5 \mu \mathrm{s})$. This demonstrated that the location error is c times the residual error provided the lightning occurs inside the area bounded by the sites receiving it. Using the yellow line as a boundary, giving a trapezoidal shape to enclosed area, the location error was nearer $2 \mathrm{~km}$ at the SE end near Dunedin. This was reasonably consistent with our (center-ofa-square) model, which would have an error of $\sim 2 \mathrm{~km}$. The important feature of Figure 2 is the way the accuracy changed outside the area bounded by the lines: the area surrounded by the lightning sensors.

The decrease in accuracy (increase in location error) changed slowly outside the midpoint of a boundary, but quickly outside a corner (a receiving site) of the bounded area, depending on the sharpness of the corner. The angles at Perth and Singapore are $\sim 120^{\circ}$, and showed a moderately sharp drop-off. The angle at Osaka is $\sim 60^{\circ}$, which gave a sharper drop-off, while that at Dunedin is $\sim 30^{\circ}$, which gave a very sharp drop-off in accuracy, and so an increase in error, in a distance of a few $\mathrm{km}$. This was consistent with our one-dimensional world, where the location of a stroke not between A and B had no accuracy (unlimited error).

All WWL locations now made available are of lightning strokes surrounded by active WWLLN sites, and have residual errors $<30 \mu \mathrm{s}$, corresponding to rms location errors $<9 \mathrm{~km}$. The residual errors were obtained from the down-hill simplex method. This provides a built-in accuracy measure (provided the lightning strokes are surrounded by WWLLN sites). Location using only three WWLLN sites, while not allowed by the down-hill simplex method and which gives rise to location ambiguities using any time-based method, provides no accuracy measure: an error in one 
time of group arrival simply results in a different location, with no indication of it being erroneous. The minimum for the down-hill simplex method is four WWLLN sites, but we found that the data quality was significantly improved by requiring more than four WWLLN sites. This loses weak strokes that are detected by the four nearest WWLLN sites but not by a fifth and more distant WWLLN site.

The relationship between the radial rms location error, $\Delta r$, and the residual error, $\Delta t$, is simply $\Delta r=c \Delta t$, where $c=0.3 \mathrm{~km} / \mu \mathrm{s}$, provided the lightning stroke is surrounded by lightning sensors. This requirement means that the lightning stroke is inside the perimeter defined by the polygon of the WWLLN sites that detected the stroke. We test for such "surroundedness" by calculating (by spherical geometry) the direction from the lightning location to each lightning sensor used in the location. The range of directions must exceed $180^{\circ}$ or else the location is rejected. Thus, all lightning locations provided to anyone have passed this test, in which case the relationship above can be used in reverse to find the error in the time of the lightning stroke, which is therefore the residual error. To see this, suppose the residual error is $30 \mu \mathrm{s}$, so the rms radial error is $9 \mathrm{~km}$. In determining the lightning location, we begin at the lightning sensor that had the earliest time of group arrival (the first WWLLN site to receive the lightning stroke). Call that site A. By GPS, we know the position of A to within a few meters, and we know the time of group arrival to within a few microseconds: let's suppose we know the time of group arrival exactly. To determine the time the lightning stroke occurred, which must be earlier than reception at $\mathrm{A}$, we must subtract the time for travel from the stoke to A (at the group velocity). However, the distance is uncertain by $9 \mathrm{~km}$, so the travel time is uncertain by $30 \mu \mathrm{s}$. Thus, $\Delta t$ is equal to the residual error, in this case $30 \mu \mathrm{s}$.

It is important to note that the necessity of "surroundedness" for adequate accuracy is not specific to the WWLLN. It applies to all lightning location networks that use timing alone for location.

\section{Detection Efficiency}

A global network has the advantage of no boundaries - every position a lightning stroke could happen at is surrounded by receiving sites - which appears to avoid the problem we had when lightning strokes as far away as Africa or America from our sixstation network could be detected but not accurately located. However, this ignores some problems. First, the ice cover on Antarctica (up to $4 \mathrm{~km}$ deep) may be a barrier to VLF propagation across it. This means that the two WWLLN sites in Antarctica (Rothera and Davis) are vital for location of lightning south of the southern continents. Second, temporary outages of one or two WWLLN sites are not uncommon, so although a lightning stroke maybe surrounded by WWLLN sites, outages of one or two might reduce the number of active sites to less than the minimum required for location. Third, a lightning stroke must be strong enough to be detected by this minimum (currently set at five) after travel of several thousand kilometers.

Although the WWLLN covers the whole world, we must limit the number of lightning strokes detected by each WWLLN site for two reasons. The first is to reduce the probability of a bunch of sferics arriving over a period of $30 \mathrm{~ms}$ not being from the same lightning stroke. If we increase the sensitivity to detect all sferics, the overlap would remove any pattern of bunches of sferics. We currently achieve this by limiting reception to an average (over a minute or so) of about three sferics per second. Since we reduce the detection rate by raising the detection threshold, this means we detect the strongest 300 sferics in a period of $100 \mathrm{sec}-$ onds (we put it like this because only the average detection rate is three per second). The computer at each WWLLN site analyses each set of 64 samples grabbed. If on analysis this set shows zero or false Earth-ionosphere waveguide dispersion, it is rejected as spurious, and does not affect the automatic threshold control setting.

Each WWLLN site has its automatic threshold control set so that it detects an average of three sferics per second, all of which pass the tests and which exceed the amplitude threshold. During the decade or so when Omega was the global navigation system (it used the VLF band, as does the WWLLN), Omega receivers occasionally reported all eight transmitters. VLF communications signals have been observed to travel the "long way around" (e.g., $30 \mathrm{Mm}$ instead of $10 \mathrm{Mm}$ ) [10]. This may also happen in the WWLLN, so we reject lightning locations from a set of times of group arrival if they include one corresponding to an Earth-ionosphere waveguide travel beyond $13.3 \mathrm{Mm}$ (one-third the way around the Earth). This limit is imposed lest the actual travel is the long way around $(26.7 \mathrm{Mm})$ at much lower attenuation.

From this, we concluded that each WWLLN site detects an average of three lightning strokes per second from distances up to 13.3 Mm (one-third the way around the world). This corresponds to $75 \%$ of the world's surface where lightning happens, so that the WWLLN has access to an average of four lightning strokes per second from the whole world (deduced from $3 / \mathrm{s}$ from $75 \%$ of the world). If all these were located, it would be the maximum possible, so in this sense the efficiency would be $100 \%$.

During the 31 days of May, 2007, the number of lightning locations by the WWLLN during each day ranged from 123,471 on May 28, to 233,962 on May 13, corresponding to 24 hour averages of $1.43 / \mathrm{s}$ and $2.71 / \mathrm{s}$, respectively. The average over the whole month was $1.75 / \mathrm{s}$. In terms of the maximum possible of locating every stroke accessible to WWLLN (4/s), the efficiency ranged from $36 \%$ (May 28) to $68 \%$ (May 13), with the May average of $44 \%$. Taking the global flash rate [5] as $100 / \mathrm{s}$ (all flashes with peak currents $>1 \mathrm{kA}$ ), then $4 / \mathrm{s}$ implied the strongest $4 \%$ of flashes. About $4 \%$ of flashes have peak currents $>70 \mathrm{kA}$ [2], so we might claim that WWLLN locates about $45 \%$ of flashes having peak currents above $70 \mathrm{kA}$.

We stress that the WWLLN was never intended to locate all lightning, so the conventional definition of "efficiency" has little relevance. On the other hand, we have introduced checks to exclude from our records any lightning locations that do not meet our standards of accuracy.

\section{World Map}

Figure 3 is a four-panel world map. Each panel is the whole world on the same day (May 1, 2007), and shows the 30 WWLLN sites from left to right (increasing longitude): Honolulu, Tahiti, Seattle, LANL, Mexico, Peru, MIT, Rothera; Puerto Rico, Cordoba, Sao Paulo, Ascension I, Lisbon, Sheffield, Budapest; Hermanus, Sodankyla, Durban, Tel Aviv, Moscow, Davis, Lanzhou; Singapore, Perth, Darwin, Osaka, Kingston, Brisbane, Dunedin, Suva. These are separated in this list by commas, except that where two sites in this list have nearly the same longitude but are in opposite hemispheres (e.g., Rothera; Puerto Rico), they are 
separated by semicolons. These sites are indicated by white circles, inside of which is red asterisk if that site was active at that time. Only one site (MIT) was inactive, and that was only at 00:00 UT.

Each panel shows a 40-minute period prior to 00:00 UT, 06:00 UT, 12:00 UT, 18:00 UT. The 40-minute period was divided into four periods of 10 minutes by the color of the lightning strokes, which are shown as dots. Those occurring during the latest 10 minutes, ending in the time shown in the heading of the panel, are blue and larger. For example, the bottom-left panel shows strokes occurring during the 40 minutes from 11:20 UT to 12:00 UT. Those occurring during $11: 20$ to $11: 30$ are red dots, those occurring during 11:30 to 11:40 are yellow dots, those occurring during 11:40 to 11:50 are green dots, and those occurring during 11:50 to $12: 00$ are larger blue dots.

The colored dots were plotted in reverse order, obscuring later dots plotted beneath: first the most recent (large blue, $240 \mathrm{~km}$ diameter as measured on the surface of the Earth, so the dot diameter can be used as a scale), then the smaller green, yellow, and red (all $120 \mathrm{~km}$ diameter), in that order. If there was a lightning stroke in the same place in each of the four 10-minute periods, the large blue dot appears with the red dot in its center. If all were precisely in the same place, the red dot would hide the green and yellow dots. When the alignment was not within $15 \mathrm{~km}$, the yellow dot was not completely obscured (but may obscure the green dot), so a thin ( $15 \mathrm{~km}$, corresponding to one pixel) crescent is visible. An example is shown in Figure 4.

The terminator, the sunrise-sunset curve, is a great circle, but appears on this projection as a quasi-sinusoidal white curve. The grey part is the part of the Earth's surface in daylight, while the black part is at night. Note that in all figures, including those below, the terminator moves left with time. If night (black) is on the right side, the terminator marks sunset. If night is on the left side, the terminator marks sunrise. Figures 4,5 , and 6 have all been made from Figure 3 by expanding the PDF of Figure 3, making a screen shot of the section required, and suitably cropping it. This is to illustrate the versatility of the WWLLN world maps, but for serious research, one requires the tabulated data.

At this time of the year (May 1, about six weeks after the equinox), it was spring in the northern hemisphere, and autumn (fall) in the southern hemisphere. Above $80^{\circ} \mathrm{N}$, it was continuously sunlit, and it was continuously nighttime at southern latitudes south of $80^{\circ} \mathrm{S}$. Lightning at mid-latitudes over land tends to be most common in the local summer. This time of the year is spring for the USA and Europe, and autumn (fall) for Australia. At low latitudes near the equator, there is always lightning, mainly on the summer side.

In middle latitudes, lightning over land tends to occur in local late afternoon and early evening. The top-left panel shows the world at 00:00 UT, and so it was local midnight in England and west Africa, but near sunset in the Americas. Lightning appeared in the Amazon basin, and also in the USA south of the Great Lakes, west of Boston. The bottom-left panel shows the world at 12:00 UT, and so midday in England and west Africa, but near sunrise in the Americas. There was almost no lightning in the Amazon basin or over land in the USA, although there was a bunch of lightning over the Atlantic Ocean about $1500 \mathrm{~km}$ east of Boston.

All panels showed lightning near Panama at all times of the day. A similar lack of diurnal variation appeared in the Indonesian archipelago and equatorial Africa. However, closer examination showed that near sunrise, the lightning tended to occur over the sea, while near sunset, the lightning tended to occur over land. This is illustrated at these times in Figures 5 and 6.

As seen on all four panels of Figure 3, lightning in the midPacific was common near Tahiti. Winter lightning was virtually non-existent over mainland Australia, but common over the 2000-km wide Tasman Sea, between Australia and New Zealand. There was clear evidence that strokes over sea were often stronger than strokes over land, thus winter lightning over both the Japan Sea and the Pacific Ocean near Japan was frequently strong enough to trigger sprites (optical phenomenon requiring darkness to observe) and trimpis (localized ionospheric perturbations) [11]. The study of positive and negative strokes over the Gulf Stream showed that lightning over the ocean was more intense than over the North American continent [12].

Winter storms over the eastern coast of the Mediterranean showed a similar diurnal variation, as seen in Figures 5 and 6 for equatorial regions (where there is no winter). The maximum in lightning activity over the sea was at 0500 LST (local solar time), and over land at 1300 LST [13].

As explained above, the WWLLN locates only strong lightning (peak currents $>70 \mathrm{kA}$ ), so lightning locations over sea might feature more prominently in WWLLN data than in other lightninglocation systems. This is mainly because land-based MF systems cannot accurately locate lightning over sea unless the sea is surrounded by the system, but partly because such systems locate lightning with peak currents over $5 \mathrm{kA}$, which amount to $80 \%$ of lightning [10].

It is perhaps surprising how much can be seen on a single day on the world map: the diurnal and seasonal variation of lightning occurrence over land at mid-latitudes; the very different, almost anti-phase diurnal and seasonal variation of occurrence over the sea; and curious lightning occurrences over mid-ocean.

\section{A Summary of Research Results with the WWLLN}

We consider these results under three categories: regional detection efficiency, global network coverage of tropical "chimneys," and targeted geophysical/meteorological studies.

\subsection{Regional Detection Efficiency for the WWLLN}

A number of investigations have combined local lightningnetwork observations [14-19] to make estimates of the detection efficiency of the WWLLN in these regions. These were primarily for ground flashes, but the last of these used lightning observations from space. Key aspects of these studies are summarized in Table 1. In judging the significance of these numbers, certain qualifications need be considered, as summarized in the final column of the table. The initial investigation by Lay [14] was characterized as a "worst-case scenario" because it was undertaken in Brazil, where the WWLLN network coverage at that time (and see Table 2) was quite limited. The detection efficiency for ground flashes was found to be $0.3 \%$. This study also first identified the 
Table 1. A summary of studies on local WWLLN detection efficiency.

\begin{tabular}{|c|l|c|c|c|}
\hline Study & Location & Local Network & $\begin{array}{c}\text { Detection } \\
\text { Efficiency }\end{array}$ & Qualifications \\
\hline$[14]$ & Brazil & Brazil Integrated Network (BIN) & $0.3 \%$ & CG flashes \\
\hline$[15]$ & Australia & Kattron & $1 \%$ & CG flashes \\
\hline$[16]$ & Australia & Kattron & $25 \%$ & $\begin{array}{c}\text { Single day } \\
\text { (IC+CG flashes) }\end{array}$ \\
\hline$[17]$ & USA & Los Alamos Sferic Array (LASA) & $4 \%$ & $I_{p}>40 \mathrm{kA}$ \\
\hline \multirow{2}{*}[18]{} & New & New Zealand Lightning Detection & $1 \%$ & $\begin{array}{c}\text { IC flashes } \\
\text { (IC+CG flashes) } \\
\end{array}$ \\
\multirow{2}{*}[19]{} & Sealand & Network (NZLDN) & $10 \%$ & $I_{p}>50 \mathrm{kA}$ \\
\hline
\end{tabular}

Table 2. WWLLN Expansion: Station numbers by year and hemisphere.

\begin{tabular}{|c|c|c|c|}
\hline Year & $\begin{array}{c}\text { Eastern } \\
\text { Hemisphere }\end{array}$ & $\begin{array}{c}\text { Western } \\
\text { Hemisphere }\end{array}$ & Reference \\
\hline 2004 & 9 & 2 & {$[15]$} \\
\hline 2005 & 12 & 6 & {$[16]$} \\
\hline 2006 & 14 & 6 & {$[17]$} \\
\hline 2006 & 13 & 9 & {$[18]$} \\
\hline
\end{tabular}

increase of WWLLN detection efficiency with lightning peak current.

In later work by Rodger [18] in New Zealand, the detection efficiency was found to be larger by an order of magnitude in the Eastern Hemisphere, where the WWLLN station density is maximum (see Table 2) $[16,18]$. Rodger also estimated the detection efficiency for IC (intracloud) strokes with the New Zealand Lightning Detection Network, and found that $10 \%$ of these events were detected by the WWLLN [18].

Jacobson [17], using both the Los Alamos Sferics Array (LASA) and the National Lightning Detection Network in the US, showed detection efficiency as a function of lightning peak current. This indicated an asymptote at about $4 \%$ as peak current continued to increase. These results suggest a problem with data processing rather than signal strength in further improvements of detection efficiency toward the long-term WWLLN goal of $50 \%$ for cloudto-ground lightning [15].

The most recent study in detection efficiency [19] used a satellite platform for comparison. The detection efficiencies (WWLLN/FORTE) in Table 1 are lower than other results in the table, simply because the FORTE satellite is a superior detector of intracloud lightning, whereas the WWLLN is a superior a detector for ground flashes. In all other studies in Table 1, ground-flash networks were used as "truth."

\subsection{Global Network Coverage}

One important measure of this network's success at worldwide lightning location is in its documentation of the Earth's most prominent regional lightning features: the tropical "chimneys." These three prominent land regions - the Maritime Continent, Africa, and the Americas - figure prominently in the modulation of the global electrical circuit [20] and the "Carnegie Curve" of atmospheric electricity. Analysis of global thunder days [21] and the satellite optical measurements [22-24] have shown a consistent climatological ranking of the lightning counts, with Africa generally dominating, and the Maritime Continent (despite its large area) in third place.

Three well-defined spatial maxima in lightning were apparent in all global maps produced by the WWLLN since 2004, but the measured relative strengths of the three maxima were clearly influenced by the heterogeneity of station locations. The maturation of the WWLLN over time was quantified in a series of publications [15-18]. These results are summarized in Table 2, which also includes the number of stations in the Eastern and Western Hemispheres over time.

The station density in the Eastern Hemisphere (where the network originated, in New Zealand) has dominated from the outset. In the first WWLLN study [16] to produce a global map, the lightning in the Maritime Continent dominated that in South America (where the continental station density was least) by a factor of two. In the most recently published global map [18], using more than four times as many stations in the Western Hemisphere as in 2004, the Americas increased in relative importance, and were showing $\sim 80 \%$ as many flashes as the Maritime Continent. Africa, the dominant lightning chimney in other studies, remained in third place with the most recent network configuration, but only a single WWLLN station was then in place within the African continent.

The foregoing results and the general requirement that five stations be involved in a reliable WWLLN network lightning location make it apparent that more-uniform station density is needed for representative global mapping of lightning flashes, at least with data-processing methods currently in place. However, network expansion is currently in the works toward remedying this situation.

\subsection{Targeted Geophysical and Meteorological Studies with the WWLLN}

Several recent publications have made use of the WWLLN as the main observational component of the investigation $[25,19,26-$ 28]. These studies are reviewed in turn.

Holzworth et al. [25] investigated the role of lightning in the global electrical circuit. Comparisons of the vertical current density 

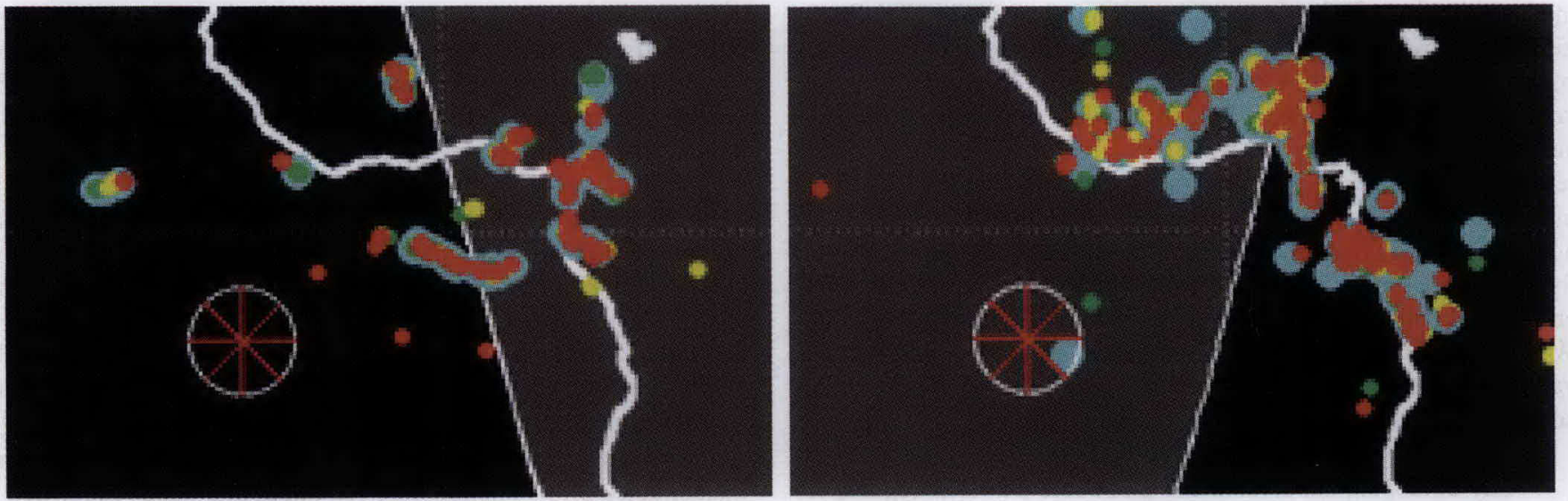

Figure 5. Enlarged sections from the panels of Figure 3, showing the equatorial West Africa coast. The WWLLN site is Ascension I. The left panel was at 00:60 UT, which was also local time. The terminator marks sunrise and crossed the equator (horizontal line) where the zero meridian (longitude $=0^{\circ}$ ) intersected the equator. The grub shape of lightning locations over the sea spread in time over the full $\mathbf{4 0}$ minutes and over the sea by a few hundred $\mathbf{k m}$. In each of over 10 positions, at least one, but probably several, lightning strokes occurred in each of the four 10-minute periods. In the right panel, the terminator marked the sunset. The time was 18:00 in both UT and local. This enlargement was also taken from Figure 3 (the 18:00 UT panel). In this case, there was more lightning, and most of it was over land, just inland from the coast.
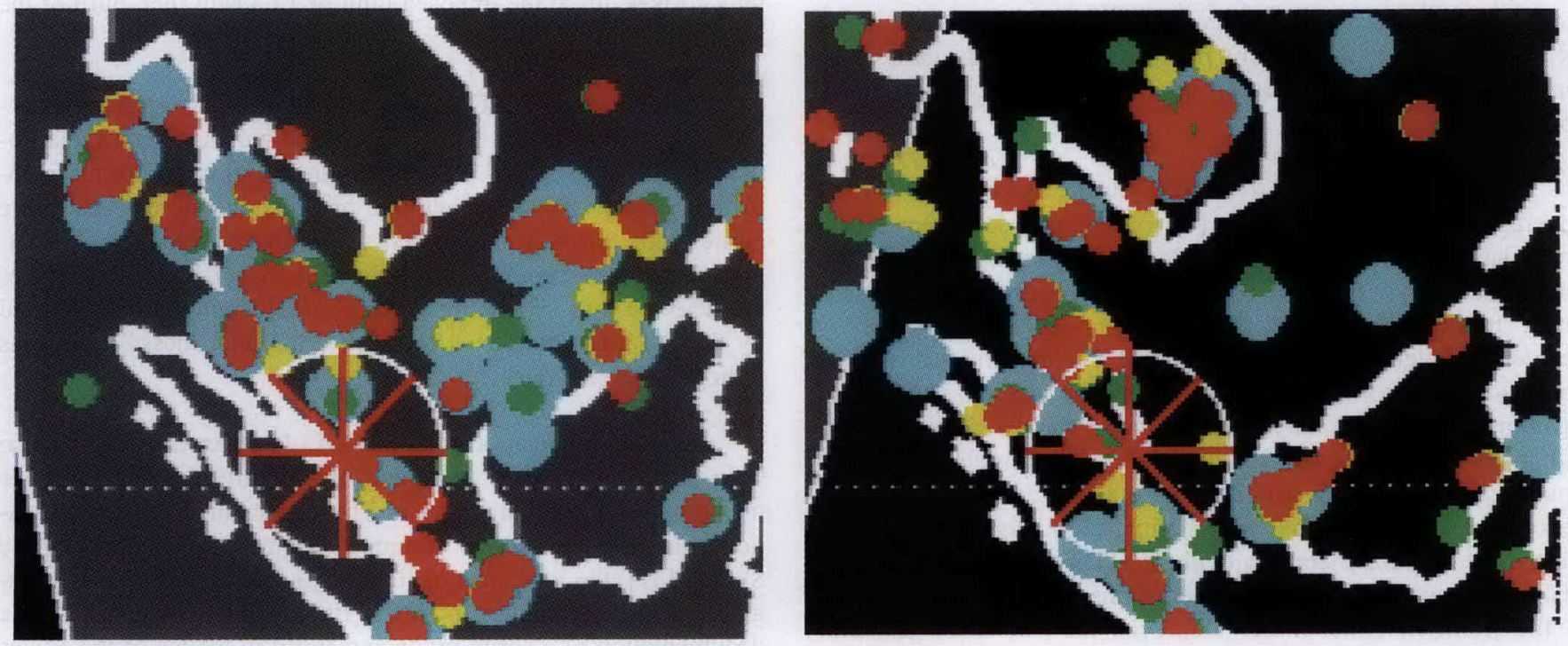

Figure 6. Sections from the 00:00 UT and 12:00 UT panels of Figure 3, enlarged more than in Figure 5. The dotted horizontal line is the equator, $120^{\circ} \mathrm{E}$ longitude is the right-hand border of both panels, and the WWLLN site was Singapore. Local solar time spanned from 6 am (sunrise) to 8 am for the left panel, and $6 \mathrm{pm}$ (sunset) to $8 \mathrm{pm}$ for the right panel. The three main landmasses are Thailand-Vietnam (upper left), Indonesia (lower left), and Borneo (lower right). As in Figure 5, lightning was mainly over the sea at 7 am and over land at $7 \mathrm{pm}$. 
in the stratosphere over Antarctica with integrated WWLLN lightning counts were made over a two-week time interval. These two continuous time series were dominated by a pronounced diurnal variation in both quantities. The diurnal variation of current density varied by more than a factor of two, in contradiction to other results on the diurnal variation of the global circuit [29]. The measured correlation was undoubtedly dominated by the pronounced diurnal signal in both quantities. Phase comparisons over the UT diurnal cycle were problematic because of the present heterogeneous coverage of the three tropical chimneys by the WWLLN, as discussed earlier. Further studies of this kind will be valuable when a more-uniform station density is achieved, so that correlations for individual tropical chimneys are possible.

Lay et al. [19] subdivided the globe into six large regions to investigate the relative local diurnal variation of lightning activity with WWLLN observations. Despite the evidence that the majority of WWLLN detections were larger-than-average-peak-current flashes to ground, the general diurnal amplitude variations and phase of these measured variations were broadly consistent with results in other studies involving both ground-based observations of CG (cloud-to-ground) activity [30] and satellite-based observations of total lightning activity [31]. For land, regions the amplitude variations were pronounced (factors of five to 10), with maxima consistently in the late afternoon, in agreement with the classical analysis of the global electrical circuit using thunder day data [20]. Regional variations in the phase of maximum activity were apparent, and were likely related to the variable mix of convective and mesoscale thunderstorms. The oceanic records in all six regions had comparatively flat diurnal amplitude variations, consistent with other studies on total lightning activity observed from space $[31,22]$.

Ortega and Guignes [26] made valuable use of the WWLLN coverage over the Pacific Ocean (where lightning documentation is unavailable from other networks) to investigate the seasonal and inter-annual behavior of the South Pacific Convergence Zone. This major tropical convective feature, extending zonally for sixty degrees of longitude, is an extension of the inter-tropical convergence zone in the western Pacific Ocean. The seasonal variation of lightning features generally followed the seasonal variation in rainfall, with maxima in the southern summer, consistent with the South Pacific Convergence Zone's southern hemisphere prominence. The WWLLN-observed lightning activity tended to be associated with more-moderate rainfall rates. On the inter-annual time scale, four years of WWLLN observations showed this long band in the warm El Niño phase. This behavior was consistent with inferences drawn from Schumann-resonance observations [32-33] concerning the inter-annual variations in the latitudinal position of the global tropical lightning over the ENSO (El Niño-southern oscillation) time scale.

Solarzano et al. [27] also exploited the oceanic lightning coverage provided by the WWLLN to investigate lightning variations in tropical cyclones. As with other studies over oceans with land-based VLF networks [34], the lightning in hurricanes and typhoons was comparatively rich for this special mode of oceanic convection. The spatial resolution of the WWLLN was just adequate to distinguish lightning origins in the convective eyewall region and in the outer rain bands. The rain bands were shown to be the dominant feature in the lightning production from such storms, and this was perhaps consistent with the evidence that the predominant WWLLN target is high-peak-current ground flashes. The phase relationships shown there between bursts of electrical activity and the deepening of these storms were somewhat less well defined than what was demonstrated recently with LASA observations [35] and additional unpublished observations by Los Alamos National Laboratory. This was probably because intracloud lightning was more prevalent in this data set, and is a consistently better indicator of convective development.

Despite the evidence for under-representation of African lightning activity in the current WWLLN station configurations [18-19], Price et al. [28] identified an interesting precursory signal in East African lightning several thousand kilometers upstream of hurricane activity off the west coast in the Atlantic Ocean, by examining daily flash counts there. Given the well-established westward progression of storm systems in African easterly waves (AEWs), these results supported new ideas that the origin and maintenance of the African easterly waves are more clearly tied to the moist convection within them than to the baroclinic instability of a zonal jet [36]. This study by Price et al. [28] was included in Discover magazine's list of 50 most important findings in 2007.

\section{Conclusions}

The WWLLN covers the whole world with a single set of lightning sensors and redundant lightning data processors, all having the same design and software. The use of VLF propagation in the Earth-ionosphere waveguide allows detection of strong lightning strokes, up to the imposed limit of $13.3 \mathrm{Mm}$ (one-third of the way around the world).

Using only the VLF electric field allows such lightning detection in urban areas on a $1 \mathrm{~m}$ whip antenna with adequate signal-tonoise ratio. All of the WWLLN sites are on university or researchinstitute campuses, observatories, or Antarctic bases. Using the entire globe, there are no borders to the area covered, so all lightning strokes are surrounded by lightning sensors, but not all strokes are detected by surrounding sensors. All lightning strokes located by the WWLLN are tested for such "surroundedness." Locations failing the test are rejected.

The continuously available WWLLN observations have also been profitably used in a number of scientific investigations for meteorological/lightning context. These cases include the observation of an unusual transient luminous event from the NASA Space Shuttle [37], the incidence of lightning-generated whistlers propagating between conjugate points in Europe and in Africa [38], the documentation of a sprite-producing storm in the lee of the Andes in Argentina [39], the application of lightning sensing to the warning of severe weather [40], the characterization of sprite-parent lightning flashes in wintertime over the Mediterranean Sea [41], the initial detection of sprites over China [42], the documentation of a negative ground flash causal to a sprite-halo [43], and as a proxy global map of sprite activity [44]. The convenient use of the WWLLN as support for these and other kinds of analyses is expected to continue and expand.

\section{References}

1. R. B. Bent and W. A. Lyons, "Theoretical Evaluations and Initial Operational Experiences of LPATS (Lightning Position and Tracking System) to Monitor Lightning Ground Strikes Using a Time-of-Arrival (TOA) Technique," Proc. VII International Con- 
ference on Atmospheric Electricity, June 3-8, Albany, NY, 1984, pp. 317-328.

2. Martin A. Uman, Lightning, Mincola, NY, Dover Publications, 1984.

3. R. L. Dowden, J. B. Brundell, and C. J. Rodger, "VLF Lightning Location by Time of Group Arrival (TOGA) at Multiple Sites," $J$. Atmos. Sol. Terr. Phys., 64, 2002, pp. 817-830.

4. E. R. Swanson, "Omega," AGARD Symposium on Medium, Long and Very Long Wave Propagation, 36, 1981, pp. 1-36:16.

5. V. A. Rakov and M. A. Uman, "Lightning: Physics and Effects," Cambridge, Cambridge University Press, 2003.

6. A. D. Watt, VLF Radio Engineering, Oxford, Pergamon Press, 1967.

7. D. J. Malan, Physics of Lightning, London, The English Universities Press, Ltd., 1963.

8. E. T. Pierce, "Atmospherics and Radio Noise" in R. H. Golde (ed.), Lightning 1: Physics of Lightning, 1977, pp. 351-384.

9. J. A. John, and R. Mead, "A Simplex Method for Function Minimization," Comput. J., 7, 1965, pp. 303-333.

10. W. M. McRae and N. R. Thomson, "VLF Phase and Amplitude: Daytime Ionospheric Parameters," J. Atmos. Sol.-Terr. Phys., 62, 7, 2000, pp. 609-618.

11. T. Otsuyama, J. Manabe, M. Hayakawa, and M. Nishimura, "Characteristic of Subionospheric VLF Perturbations Associated with Winter Lightning Around Japan," Geophys. Res. Lett., 31, 2004, L04117, doi:10.1029/2003GL019064.

12. K. R. Biswas, and P. V. Hobbs, "Lightning over the Gulf Stream,” Geophys. Res. Lett., 17, 7, 1990, p. 941.

13. O. Altaratz, Z. Levin, Y. Yair and, and B. Ziv, "Lightning Activity over Land and Sea on the Eastern Coast of the Mediterranean," Mon. Wea. Rev., 131, 2003, pp. 2060-2070.

14. E. H. Lay, R. H. Holzworth, C. J. Rodger, J. N. Thomas, O. Pinto, Jr., and R. L. Dowden, "WWLL Global Lightning Detection System: Regional Validation Study in Brazil," Geophys. Res. Lett., 31, 2004, L03102, doi:10.1029/2003GL018882.

15. C. J. Rodger, J. B. Brundell, R. L. Dowden, and N. R. Thomson, "Location Accuracy of Long-Distance VLF Lightning Location Network," Ann. Geophys., 22, 2004, pp. 747-758.

16. C. J. Rodger, J. B. Brundell, and R. L. Dowden, "Location Accuracy of VLF World Wide Lightning Location (WWLL) Network: Post-Algorithm Upgrade," Ann. Geophys., 23, 2005, pp. 277-290.

17. A. R. Jacobson, R. H. Holzworth, J. Harlin, R. L. Dowden and E. H. Lay, "Performance Assessment of the World Wide Lightning Location Network (WWLLN), Using the Los Alamos Sferic Array (LASA) Array as Ground-Truth," Journal of Atmospheric and Oceanic Technology, 23, 2006, pp. 1082-1092.
18. C. J. Rodger, S. Werner, J. B. Brundell, E. H. Lay, N. R. Thomson, R. H. Holzworth, and R. L. Dowden, "Detection Efficiency of the VLF World-Wide Lightning Location Network (WWLLN): Initial Case Study," Ann. Geophys., 24, 2006, pp. 3197-3214.

19. E. H. Lay, A. R. Jacobson, R. H. Holzworth, C. J. Rodger, and R. L. Dowden, "Local Time Variation in Land/Ocean Lightning Count Rates as Measured by the World Wide Lightning Location Network," J. Geophys. Res., 112, 2007, D13111, doi:10.1029/2006JD007944.

20. F. J. W. Whipple, "On the Association of the Diurnal Variation of Electric Potential Gradient in Fine Weather with the Distribution of Thunderstorms Over the Globe," Quart. J. Roy. Met. Soc., 55, 1929, pp. 1-17.

21. C. E. P. Brooks, "The Distribution of Thunderstorms Over the Globe," Geophys. Mem. London, 24, 1925, pp. 147-164.

22. H. J. Christian, R. J. Blakeslee, D. J. Boccippio, W. L. Boeck, D. E. Buechler, K. T. Driscoll, S. J. Goodman, J. M. Hall, W. J. Koshak, D. M. Mach, and M. F. Stewart, "Global Frequency and Distribution of Lightning as Observed from Space by the Optical Transient Detector," J. Geophys. Res., 108, 2003, 4005, doi: 10.1029/2002JD002347.

23. E. R. Williams, and G. Sátori, "Lightning, Thermodynamic and Hydrological Comparison of the Two Tropical Continental Chimneys," J. Atmos. Sol. Terr. Phys., 66, 2004, pp. 1213-1231.

24. J. C. Bailey, R. J. Blakeslee, D. E. Buechler and H. J. Christian, "Diurnal Lightning Distributions as Observed by the Optical Transient Detector and the Lightning Imaging Sensor (LIS)," 13th Int'1 Conf on Atmos. Elec., Beijing, China, August, 2007, pp. 657-660.

25. R. H. Holzworth, E. A. Bering III, M. F. Kokorowski, E. H. Lay, B. Reddell, A. Kadokura, H. Yamagishi, N. Sato, M. Ejiri, H. Hirosawa, T. Yamagami, S. Torii, F. Tohyama, M. Nakagawa, T. Okada, and R. L. Dowden, "Balloon Observations of Temporal Variation in the Global Circuit Compared to Global Lightning Activity," Advances in Space Research, 36, 2005, pp. 2223-2228.

26. P. Ortega and T. Guignes, "Lightning Activity Analyses with Respect to the SPCZ Location," Geophys. Res. Lett., 34, 2007, L11807, doi:10.1029/2007GL029730.

27. N. N. Solorzano, J. N. Thomas, and R. H. Holzworth, "Global Studies of Tropical Cyclones Using the World Wide Lightning Location Network," AMS Annual Meeting 2008 in New Orleans, January 2008.

28. C. Price, Y. Yair, and M. Asfur, "East African Lightning as a Precursor of Atlantic Hurricane Activity," Geophys. Res. Lett., 34, 2007, L09805, doi:10.1029/2006GL028884.

29. E. R. Williams, "The Global Electrical Circuit: A Review," Atmospheric Research, 2008 (in review).

30. E. R. Williams and S. J. Heckman, "The Local Diurnal Variation of Cloud Electrification and the Global Diurnal Variation of Negative Charge on the Earth," J. Geophys. Res., 98, 1993, pp. , 5221-5234. 
31. G. Satori, and B. Zieger, "El Nino-Related Meridional Oscillation of Global Lightning Activity," Geophys. Res. Lett., 26, 1999, pp. $1365-1368$.

31. E. R. Williams, K. Rothkin, D. Stevenson, and D. Boccippio, "Global Lightning Variations Caused by Changes in Thunderstorm Flash Rate and by Changes in the Number of Thunderstorms," $J$. Appl. Met., 39, 2000, pp. 2223-2248.

33. H. Yang, and V. Pasko, "Power Variations of Schumann Resonances Related to El Nino and La Nina Phenomena," Geophys. Res. Lett., 34, 2007, L11102, doi:10.1029/2007GL030092.

34. T. Chronis, E. Williams, M. Anagnostou, and W. Petersen, "African Lightning: Indicator of Tropical Atlantic Cyclone Formation," EOS, Transactions, American Geophysical Union, 88, 40, 2007, pp. 397-408.

35. X. M. Shao et al., "Katrina and Rita were Lit Up with Lightning," EOS, 86, 42, 2005, p. 398.

36. C. D. Thorncroft, N. Hall, and G. Kiladis, "Three-Dimensional Structure and Dynamics of African Easterly Waves, Part III: Genesis," J. Atmos. Sci., 2008 (in revision).

37. Y. Yair, C. Price, B. Ziv, P. L. Israelevich, D. D. Sentman, F. T. Sao-Sabbas, A. D. Devir, M. Sato, C. J. Rodger, M. Moalem, E. Greenberg, and O. Yaron, "Space Shuttle Observation of an Unusual Transient Atmospheric Emission," Geophys. Res. Lett., 32, 2, 2005, 10.1029/2004GL021551.

38. A. B. Collier, A. R. W. Hughes, J. Lichtenberger, and P. Steinbach, "Seasonal and Diurnal Variation of Lightning Activity Over Southern Africa and Correlation with European Whistler Observations," Ann. Geophys., 24, 2006, pp. 529-542.

39. J. N. Thomas et al., "A Very Active Sprite-Producing Storm Observed Over Argentina," EOS Transactions, American Geophysical Union, 88, 10, 6 March, 2007, 117-128.

40. C. Price, "Lightning Sensors for Observing, Tracking and Nowcasting Severe Weather," Sensors, 8, 2008, pp. 157-170.

41. M. Ganot, Y. Yair, C. Price, B. Ziv, Y. Sherez, E. Greenberg, A. Dvir and R. Yaniv, "First Detection of Transient Luminous Events Associated with Winter Thunderstorms in the Eastern Mediterranean," Geophys. Res. Lett., 34, L12801, 2007, doi:10.1029/2007GL029258.

42. J. Yang, X. Qie, G. Zhang, Y. Zhao, and T. Zhang, "Red Sprites Over Thunderstorms in the Coast of Shandong Province, China," Chinese Science Bulletin, 53, 7, 2008, pp. 1079-1086.

43. M. J. Taylor, M. Bailey, P. -D. Pautet, S. A. Cummer, N. Jaugey, J. N. Thomas, N. N. Solorzano, S. Sao Sabbas, R. Holzworth, O. Pinto, Jr., and N. Schuch, "Simultaneous Imaging and ELF/VLF Measurements of a Sprite-Halo Driven by a Negative Lightning Discharge Over Argentina," Geophys. Res. Lett., 2008 (in press).

44. Arnone, E., A. Kero, B. M. Dinelli, C. -F. Enell, N. F. Arnold, E. Papandrea, C. J. Rodger, M. Carlotti, M. Ridolfi and E. Turunen, "Seeking Sprite-Induced Signatures in Remotely Sensed Middle Atmosphere $\mathrm{NO}_{2}$," Geophys. Res. Lett., 35, 2008, L05807, doi:10.1029/2007GL031791.

\section{Introducing the Feature Article Authors}

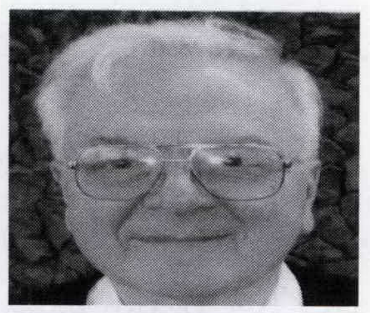

Richard Dowden was born in Australia in 1932, received his $\mathrm{BSc}$ at Sydney University and his MSc, $\mathrm{PhD}$, and DSc at the University of Tasmania, Australia. In 1966, he was appointed Professor of Physics at Otago University, Dunedin, NZ, and Emeritus Professor on retirement in 1998. He set up his company, Low Frequency Electromagnetic Research (LF*EM) in 1997, which founded the WWLLN in 2000.

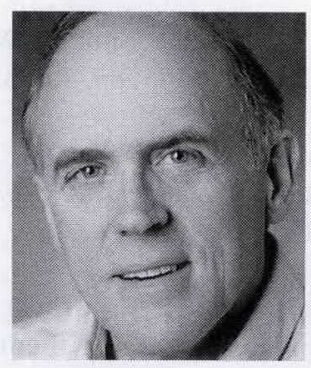

Robert Holzworth was born in North Carolina, USA, in 1950, and received his $\mathrm{BS}$ at University of Colorado and his $\mathrm{PhD}$ at University of California at Berkeley in 1977. He is now Professor in the Departments of Earth and Space Sciences, and Physics, University of Washington, USA.

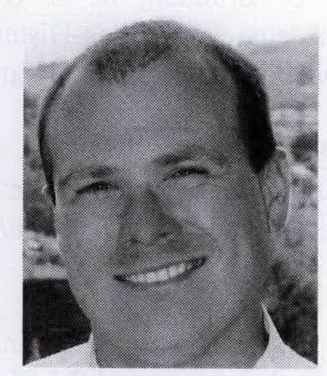

Craig Rodger was born in Wellington, NZ, in 1972, received his BSc and PhD at Otago University, Dunedin, NZ, where he is now Senior Lecturer of Physics. As well as host of the Dunedin WWLLN site, he is manager of the WWLLN's second Central Processor Computer (CPC2). 


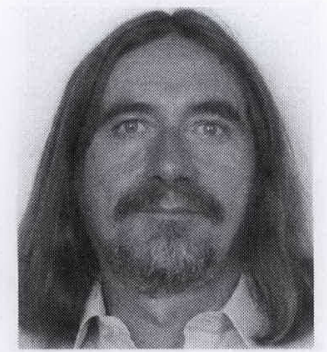

János Lichtenberger was born in Szabadhídvég, Hungary in 1956, received his $\mathrm{MSc}$ and $\mathrm{PhD}$ at Eötvös University, Budapest, Hungary, where he is now Senior Research Fellow. His current research includes whistler research, development of automatic detection and analyzes method and worldwide network. $\mathrm{He}$ is the host of Budapest WWLLN site.

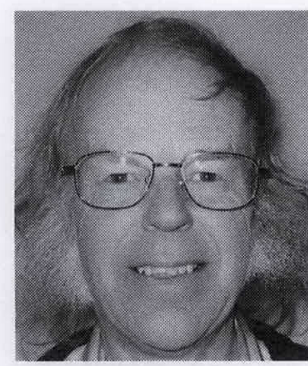

Neil Thomson was born in Dunedin, NZ, in 1945, received his $\mathrm{BSc}$ and $\mathrm{PhD}$ at Otago University, Dunedin, $\mathrm{NZ}$, where he is now Associate Professor of Physics. His current research includes VLF propagation in the EIWG and its use for solar flare measurement. He is calibrating key WWLLN sites to measure lightning stroke radiated energy.

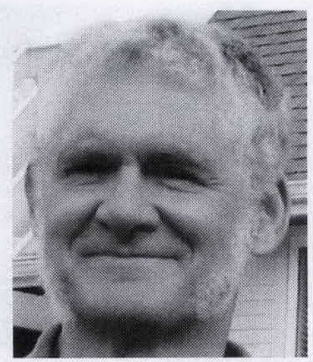

Abram Jacobson was born in Boston, USA, in 1948. He received his BA from Amherst College in 1970, and his $\mathrm{PhD}$ in Physics from Harvard University in 1974. From then until 2005, he worked at Los Alamos National Laboratory, and currently is an Affiliate Professor at the University of Washington.

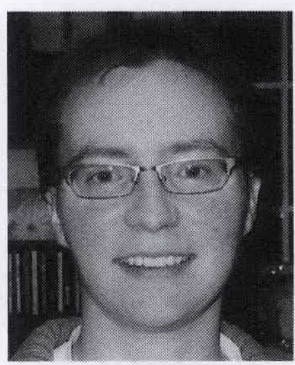

Erin Lay was born in Wisconsin, USA, in 1980, received her BA from Grinnell College and MS from University of Washington. She is in the process of pursuing her $\mathrm{PhD}$ from UW by calibrating WWLLN sites to measure lightning-stroke radiated energy and by modeling the interaction of lightning energy with the lower ionosphere.

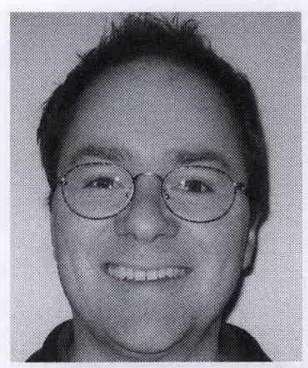

James Brundell was born in Dunedin, NZ, in 1969, received his $\mathrm{BSc}$ and $\mathrm{PhD}$ at Otago University, Dunedin, NZ. While working part time for $\mathrm{LF}^{*} \mathrm{EM}$, he wrote the lightning sensor software, which later incorporated TOGA, and the first CPC analysis software. He is now Software Engineer at ADInstruments, Dunedin, NZ.

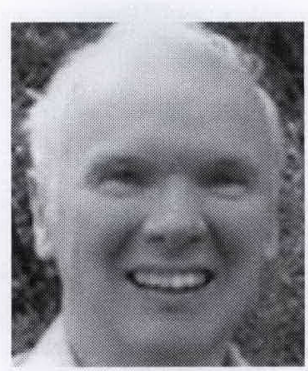

Tom Lyons was born in Australia in 1949, received his BSc at the University of Melbourne and his $\mathrm{PhD}$ at the Flinders University of South Australia. He is currently Professor of Environmental Science within the School of Environmental Science at Murdoch University, Perth, Western Australia and host of the Perth WWLLN site. 


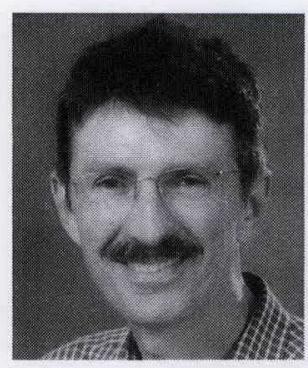

Steven O'Keefe was born in Brisbane, Australia in 1958, received his $\mathrm{PhD}$ at Griffith University in 1995 . He is now an Associate Professor in the Griffith School of Engineering, deputy director of the Centre for Wireless Monitoring and Applications, and the host of the Brisbane WWLLN site.

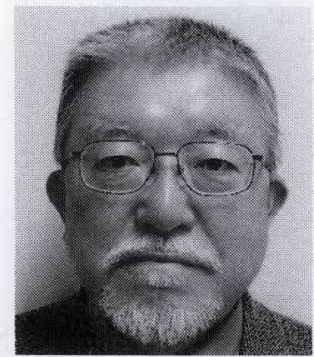

Zen Kawasaki was born in Osaka, Japan, in 1949, received his $\mathrm{BSc}$ and $\mathrm{PhD}$ at Osaka University, Osaka, Japan, where he is now Professor of Faculty of Engineering. He is the department head of Electrical, Electronics and Information Engineering. He is the president of International Committee of Atmospheric Electricity.

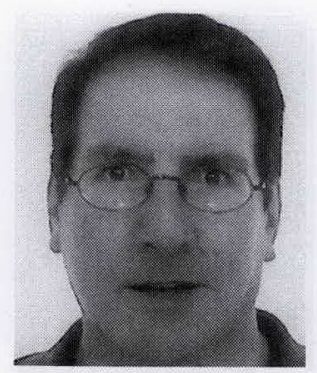

Colin Price was born in Johannesburg, South Africa, in 1962, received his BSc and MSc from Tel Aviv University, and his $\mathrm{PhD}$ from Columbia University, New York in 1993. He is now Associate Professor of Atmospheric Physics in the Department of Geophysics and Planetary Sciences, Tel Aviv University, Israel, and the host of the Tel Aviv WWLLN site.

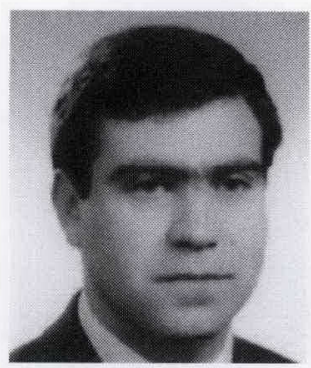

Victor Prior was born in Mêda, PT, in 1961, received his $\mathrm{BSc}$ at Aveiro University, PT, MSc at Lisboa University, and PhD at Aveiro University. He is a senior meteorologist and he was a PT manager for the National Lightning Network. Now he is the Coordinator of the Processing and Numerical Weather Prediction from the Meteorological Institute. He is also host of the WWLLN site in Portugal.

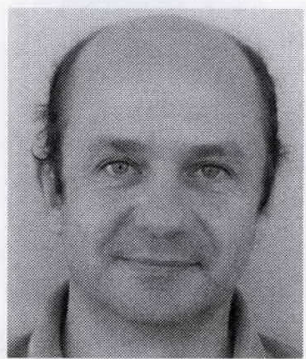

Pascal Ortéga was born in Marocco in 1962, received his $\mathrm{PhD}$ (Electrical Discharge In Long Air Gaps) at the University of Pau (France). He is now Assistant Professor at the University of French Polynesia and is the host of the Tahiti site.

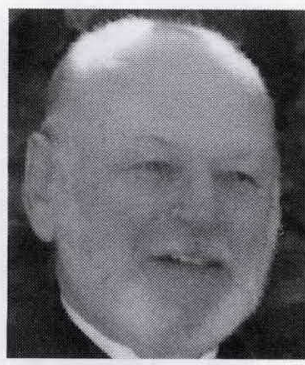

James Weinman was born in Illinois, USA, in 1930, and received his $\mathrm{PhD}$ in physics from the University of Wisconsin in 1957. He joined the Meteorology Department of the University of Wisconsin in1963 and retired as Professor Emeritus in 1987. He is currently in the Atmospheric Sciences Department at the University of Washington. He founded several of the WWLLN sites. 


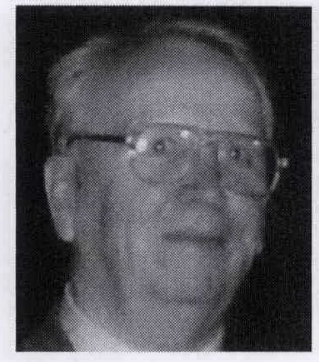

Yuri Mikhailov was born in Kologriv, Kostroma region, Russia, in 1932, received his PhD at IPE, Moscow, his ProfD at IZMIRAN. His current research includes VLF-satellite and ground based investigations. He concerned by montage of WWLLN in Troitsk, IZMIRAN, observations and interpretation of data. He is now head of VLF and electromagnetic compatibility laboratory of IZMIRAN.

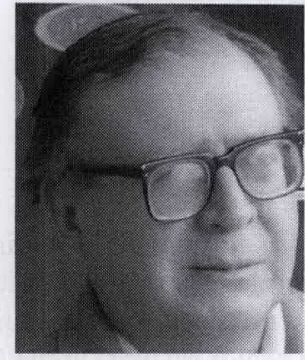

Oscar Veliz was born in Lima in 1952, worked as development engineer at the Geophysical Institute of Peru, Huancayo Observatory since 1972 . He is now working at Jicamarca Radio Observatory since 1992, operating ionospheric optical instruments and ionospheric data analysis, and the WWLLN station at Huancayo-Peru.

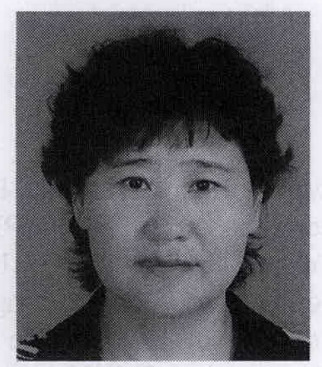

Xiushu Qie was born in Hebei, China, received her BSc in Hebei University, and $\mathrm{PhD}$ at Chinese Academy of Sciences, where she is now Professor of Atmospheric Physics. Her current research includes lightning physics and its relation to meteorology. She is a founder of China's WWLLN site at Lanzhou.

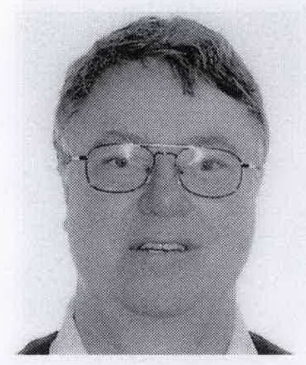

Gary Burns was born in Melbourne, Australia, in 1954. He received his $\mathrm{BSc}$ at Melbourne University and his $\mathrm{PhD}$ at LaTrobe University, Australia. He hosts the Kingston, Australia, and Davis, Antarctica, WWLLN sites, and is a Principal Research Scientist with the Australian Antarctic Division.

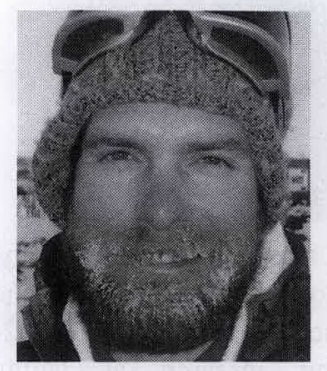

Andrew Collier was born in Durban, South Africa, in 1972. $\mathrm{He}$ received his $\mathrm{PhD}$ from the Royal Institute of Technology, Stockholm. He is employed at the Hermanus Magnetic Observatory, is Antarctic Research Fellow, Space Physics Research Institute University of KwaZulu-Natal, Durban and hosts WWLLN sites at Durban and Hermanus.

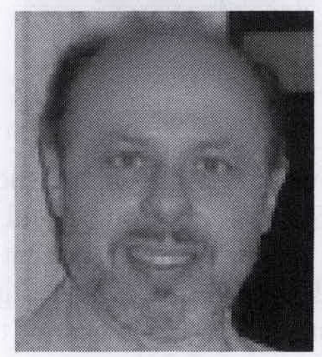

Osmar Pinto was born in Porto Alegre on September 1, 1954. He graduated in Electrical Engineering from the Pontifice Catholic University in 1977, and received his BS and $\mathrm{PhD}$ from the Brazilian Institute of Space Research (INPE) in 1979 and 1984, respectively. He is a senior scientist of INPE and the head of the Atmospheric Electricity Group of INPE. He is host of the WWLLN site in Brazil. 


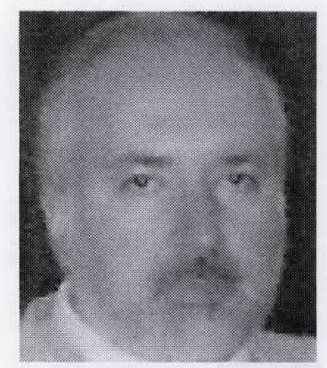

Ricardo Diaz was born in Argentina in 1955, received his electrical engineering degree (DiplIng) from the National University of Tucuman in 1980, and the H-V engineering degree (Dott) from Padua University in 1982. He is now a full professor in the National University of Tucuman and director of the High Voltage Laboratory.

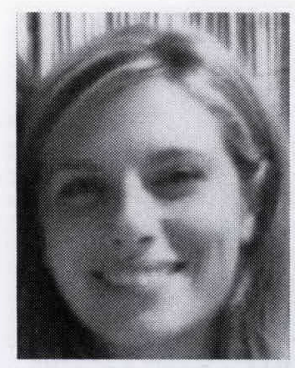

Claudia Adamo was born in Roma, Italy, in 1974, received her $\mathrm{PhD}$ at University of Ferrara, Italy. Now she is a meteorologist in the Italian Weather Channel, skymeteo24, and she's still involved in lightning research at Istituto delle Scienze dell'Atmosfera e del Clima, ISAC.

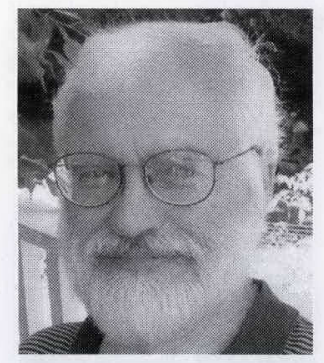

Earle Williams was born in South Bend, Indiana, in 1951, received his BA from Swarthmore College and $\mathrm{PhD}$ at MIT, where he remains a research scientist. He is currently interested in the natural variations of global lightning and the global electrical circuit on a variety of time scales. He is host of the WWLLN site at MIT near Boston, USA

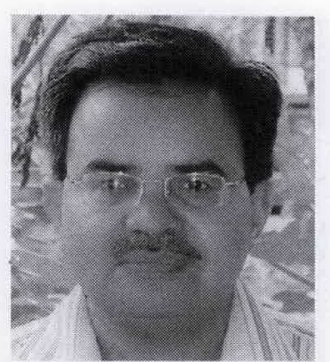

Sushil Kumar was born in India in 1968, received his BSc and MSc at the Agra University and his $\mathrm{PhD}$ at the University of Bhopal, India. He is currently Senior Lecturer of Physics within the School of Engineering and Physics at the University of the South Pacific, Suva, Fiji and host of the Suva WWLLN site.

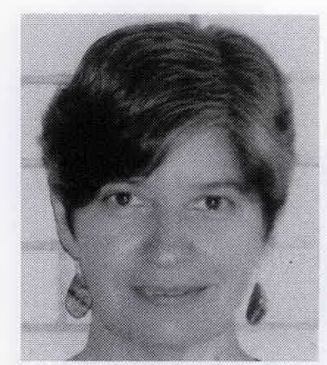

Graciela B. Raga was born in Buenos Aires, ARG, in 1959, received her Lic. in Meteorology at the University of Buenos Aires, and her $\mathrm{PhD}$ in Atmospheric Sciences at the University of Washington. She is currently a senior scientist at the Centro de Ciencias de la Atmosfera of the Universidad Nacional Autonoma de Mexico.

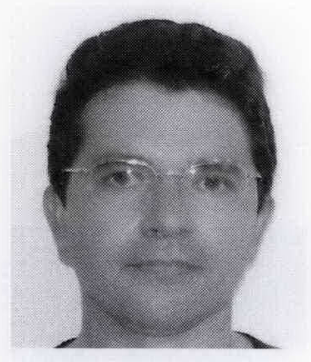

Jose Rosado was born in Cristobal, Panama Canal Zone, Panama, in 1965, received his BSEE at UPR-Mayagüez and his MEng and $\mathrm{PhD}$ at Cornell University, NY, USA. He is currently Associate Professor of Electrical Engineering at UPR-Mayagüez. His research interests focus on mid-latitude ionospheric physics. $\mathrm{He}$ is the host of the Puerto Rican WWLLN site. 


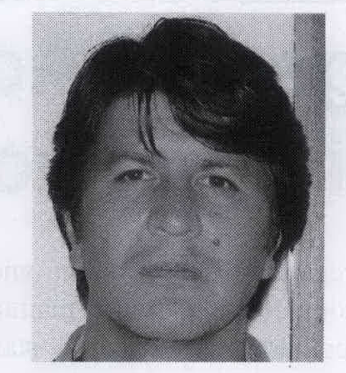

Eldo Avila was born in Leones, Córdoba, Argentina in 1962, received his $\mathrm{PhD}$ at University of Córdoba in 1994. He is now Professor in the Faculty of Mathematics Astronomy and Physics (FaMAF), University of Córdoba. His current research includes Cloud Electrification and Microphysical Processes in Clouds. He is host of Córdoba site of WWLLN.

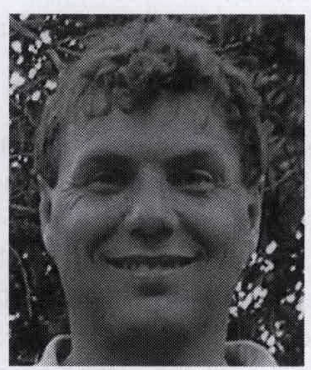

Mark Clilverd was born in Kent, England in 1963, received his BSc at the University of Southampton and his $\mathrm{PhD}$ at the University of Sheffield in 1990. He is now a Project Leader for the Physical Sciences Division of the British Antarctic Survey, and hosts the Rothera, and Ascension Island WWLLN sites.

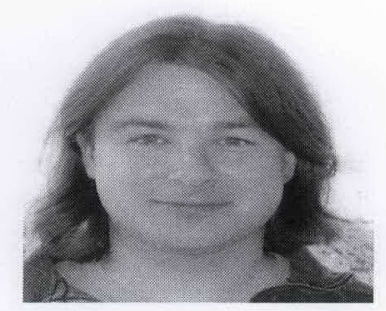

Thomas Ulich was born in Nienburg/Weser, Germany, in 1968, received his $\mathrm{MSc}$ and $\mathrm{PhD}$ from the University of Oulu, Finland. His current research interests are in ionospheric physics. Today he works at the Sodankylä Geophysical Observatory (SGO), which is an independent department of the University of Oulu, and he is host of the SGO WWLLN station.

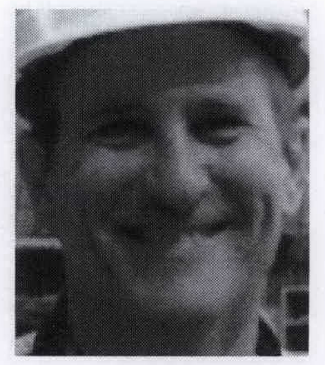

Peter Gorham graduated $\mathrm{PhD}$ Physics, University of Hawaii at Manoa 1986, Fellow and Senior Research Fellow, Caltech, 1987-1991; Research Prof. of Physics, UH, 1991-1996; Senior Member of Technical Staff, Jet Propulsion Lab, 1996-2001; Professor of Physics at Univ. Hawaii Manoa, 2001-Present. He is host of the Hawaiian WWLLN site.

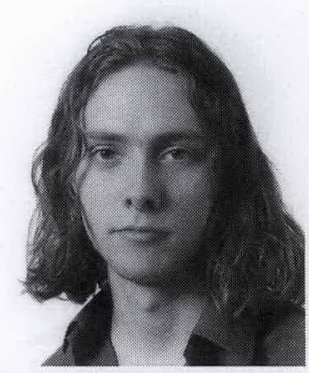

Tom Shanahan was born in Kings Lynn, UK, in 1979 and received his BSc at Exeter University, UK in 2002. Since 2004, he has worked in Edinburgh, UK, as an Instrumentation Engineer in the Geomagnetism group at the British Geological Survey.

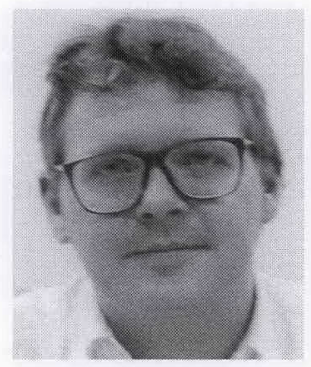

Thomas Osipowicz was born in Flieden, Germany, in 1957, received his diploma in physics in 1986, and the degree of Doktor rer. nat. in 1990 from the University of Göttingen. He is currently an Associate Professor of Physics at the National University of Singapore and host of the Singapore WWLLN site. 


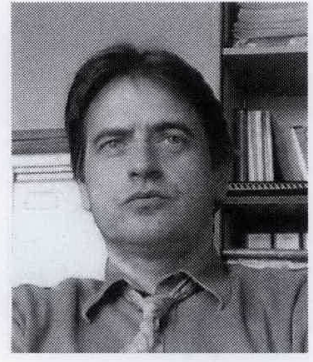

Greg Cook was born in the UK. He is currently Reader in Electromagnetics in the Electronic \& Electrical Engineering Department of Sheffield University, researching in the fields of computational electromagnetic modeling and measurements of antennas. He host of the Sheffield WWLLN site.

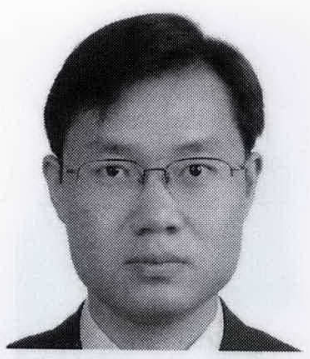

Yang Zhao was born in Shaanxi Province, China, in 1977. He received the MS degree in atmospheric physics form Chinese Academy of Sciences (CAS) in 2004, where he is currently pursuing the $\mathrm{PhD}$ degree. His research interests involve triggered lightning and lightning meteorology. $\mathrm{He}$ is the host of China's WWLLN site at Lanzhou.

\section{Changes of Address or Delivery Problems}

Information regarding subscriptions and addresses is managed by IEEE headquarters. It is not maintained, nor can it be changed, by any member of the Magazine staff. If you are a member of the IEEE, your subscription is sent to the address in your IEEE member record. Your address can be confirmed or updated by visiting the Web page dealing with delivery of IEEE publications:

http://www.ieee.org/web/aboutus/help/products_services/ subscriptions.html

This page also has information about publication delivery, and a link to an online form that can be used to inquire about missing or delayed publications.

You can also update your address information by contacting IEEE headquarters: Member Address Records, IEEE Headquarters, 445 Hoes Lane, Piscataway NJ 08855-1331 USA; Tel: +1 (908) 981-0060 or +1 (800) 678-4333; Fax: +1 (908) 981-9667; E-mail: address. change@ieee.org. If you are an institutional or other nonmember subscriber, contact IEEE Customer Service at the above address, telephone, and fax numbers; E-mail: customer.service@ieee.org.

Please do not send requests related to the above items to any member of the Magazine Staff. 